\title{
Influence of mesoscale eddies on biological production in the Mozambique Channel: Several contrasted examples from a coupled ocean-biogeochemistry model
}

\author{
Y.S. Joséa ${ }^{a, *}$, O. Aumont ${ }^{b}$, E. Machu ${ }^{b}$, P. Penven ${ }^{a, b}$, C.L. Moloney ${ }^{c}$, O. Maury ${ }^{a, d}$ \\ a Department of Oceanography, Marine Research Institute, University of Cape Town, South Africa \\ ${ }^{\mathrm{b}}$ Laboratoire de Physique des Oceans (UMR 6523 CNRS, Ifremer, IRD,UBO), LMI ICEMASA, France \\ ${ }^{c}$ Department of Zoology, Marine Research Institute, University of Cape Town, South Africa \\ d Institut de Recherche pour le Développement - UMR 212 EME, France \\ *: Corresponding author : Y. S. José, email address : yonss.jose@gmail.com
}

\begin{abstract}
:
The impact of mesoscale activity on phytoplankton and nutrient distribution in the Mozambique Channel was simulated by coupling a biogeochemical model (PISCES) with a regional oceanic model (ROMS). Examples of the effects of eddies on the biogeochemistry of the Mozambique Channel are presented to illustrate the complexity of the system. In the model, several cyclonic eddies were found with low concentrations of chlorophyll at their cores, which contrasts with previous studies in the open ocean. In addition, several anticyclonic eddies were simulated with high concentrations of chlorophyll at their cores. Phytoplankton growth within these mesoscale features (both cyclonic and anticyclonic eddies) occurred in response to nutrient injection into the euphotic zone by advection, and subsequent retention of surrounding nutrient-rich waters within eddies. Offshore nutrient distributions depended strongly on lateral advection of nutrient-rich water from the coastal regions, induced by eddy interaction with the shelf. The environmental conditions at the locations where eddies were generated had an important effect on nutrient concentrations within these structures.
\end{abstract}

Keywords : Ocean physical-biogeochemical coupling ; Cyclonic and anticyclonic eddies ; Chlorophyll; Nutrients ; Mozambique Channel

\section{Introduction}

Phytoplankton is a major component of ocean biogeochemical cycling (Broecker et al., 1982 and Sarmiento and Gruber, 2006). By maintaining primary production, phytoplankton organisms 
represent the first level of the marine food web and exert the major control on its structure and richness (Legendre and Rassoulzadegan, 1995). Primary production in the oceans is driven by the availability of nutrients in the euphotic zone where light is available for photosynthesis (Valiela, 1995), while mortality, egestion and excretion of planktonic organisms determine the fate of organic matter produced in the upper layers. This matter is exported through sedimentation and hence depletes nutrients in surface waters. Nutrients can be replenished by lateral transport from high nutrient regions and/or by vertical input from nutrient-rich intermediate waters, through the seasonal variability of the thermocline or by Ekman pumping (Sarmiento and Gruber, 2006).

In the Mozambique Channel (MC), circulation is dominated by strong mesoscale activity (de Ruijter et al., 2002) and large anticyclonic eddies have been observed to move in a southerly direction (de Ruijter et al., 2002; Schouten et al., 2003). These eddies are responsible for an average southward transport of about $15 \mathrm{~Sv}$ in the MC (de Ruijter et al., 2002). According to Schouten et al. (2003) and de Ruijter et al. $(2002,2005)$, they appear at a frequency of about 4-5 per year, with a diameter of up to $300 \mathrm{~km}$ and can extend to the bottom at $\sim 17^{\circ} \mathrm{S}$ (Schouten et al., 2003). In recent years, many studies have tried to relate marine ecosystem components to mesoscale features, notably top predators, due to the recent development of miniaturized position devices (Haney (1986); Nel et al. (2001); Weimerskirch et al. (2004); Weimerskirch (2007); Cotté et al. (2007); Tew-Kai and Marsac (2010); Scheffer et al. (2010); Cottin et al. (2012)). For example, Weimerskirch et al. (2004) found that the preferred foraging areas for frigatebirds in the MC is in the western sector of the Channel and they suggested that this preference is related to the presence of eddies. Tew-Kai and Marsac (2010) found higher chlorophyll concentrations and purse-seine tuna catches associated with mesoscale structures. At lower trophic levels, Lebourges-Dhaussy et al. (2013) investigated the impact of mesoscale eddies on zooplankton in the MC ecosystem. Based on 2 surveys conducted over 2 different years and seasons, they concluded that species composition was not significantly different between the mesoscale features that were investigated. These authors suggested that differences are mainly related to relative biovolume which seems to vary according to the life history and stability of the mesoscale structure. Huggett et al. (2013) found that biovolume was on average twice as high in cyclonic eddies compared to anticyclonic eddies, although significant variability was apparent from one year to the next.

In the open ocean, primary production can be sustained by the vertical flux of nutrients induced by the dynamics of mesoscale eddies, particularly the uplift of isopycnal surfaces in the core of cyclonic eddies that upwells nutrient-rich subsurface water into the euphotic zone (McGillicuddy 
and Robinson (1997); Oschlies and Garcon (1998); Longhurst (2001)). In an anticyclonic eddy, downwelling entrains nutrients from the euphotic zone into the aphotic zone through the deepening of isopycnal surfaces at its core (Yentsch and Phinney, 1985; Franks et al., 1986; McGillicuddy and Robinson, 1997; Longhurst, 2001). Kishi (1994) showed that only the light intensity and the balance between uptake and vertical diffusion of dissolved nutrients are important in maintaining subsurface chlorophyll maxima in anticyclonic eddies, and suggested that upwelling could occur between two anticyclonic structures. In addition, Williams and Follows (1998) suggested that eddies might enhance the lateral transport of nutrients from nutrient-rich regions to oligotrophic gyres. Along the southwestern coast of Madagascar, Quartly and Srokosz (2003) observed cyclonic eddies with low chlorophyll concentrations $\left(<0.1 \mathrm{mg} \mathrm{m}^{-3}\right)$ in their cores and enhanced chlorophyll at their periphery $\left(0.2 \mathrm{mg} \mathrm{m}^{-3}\right)$ that was derived from coastal water that had been advected offshore from coastal upwelling regions. In the Australian Leeuwin Current system, Waite et al. (2007) observed anticyclonic eddies trapping productive coastal waters in their cores. In the California and Canary Current systems, Gruber et al. (2011) demonstrated that mesoscale processes could induce lateral transport of nutrients from the nearshore region to the open ocean, reducing biological production in the coastal upwelling domain. Mesoscale eddies induced a subduction of near surface nutrients at $100-300 \mathrm{~km}$ offshore and the authors related this subduction to the weakening of the lateral eddy transport. Other processes responsible for the injection of nutrients into the surface layer are the sub-mesoscale frontal dynamics associated with mesoscale structures (Abraham, 1998; Levy et al., 2012). Lévy et al. (2001) estimated that more than $1 / 3$ of the large scale new production and phytoplankton subduction is induced by these sub-mesoscale physical processes.

The objective of this work was to analyse the life history of eddies that presented contrasting surface biological signatures. The study investigated whether the production within eddies was stimulated by vertical injection of nutrients in the eddy cores, or by offshore advection and retention of productive coastal waters. Five typical mesoscale features ( 2 cyclonic and 3 anticyclonic eddies), differing from one another in terms of chlorophyll content, were selected and analyzed. For this purpose, we used the ROMS ocean model (Regional Oceanic Modeling System; Shchepetkin and McWilliams, 2005) coupled with the PISCES biogeochemical model (Pelagic Interaction Scheme for Carbon and Ecosystem Studies; Aumont and Bopp, 2006). Both observed and simulated eddies were investigated and the processes relating to phytoplankton growth were assessed. This assisted in evaluating the contributions of vertical supply mechanisms and advection from coastal waters to sustaining primary production in the MC. 


\section{Methods}

\subsection{Model description}

ROMS is an explicit free surface ocean model based on terrain-following vertical coordinates (Shchepetkin and McWilliams, 2005). It solves the primitive equations in a rotating frame following the Boussinesq and hydrostatic approximations and using third-order precision advection schemes in space and time. The unresolved vertical mixing processes are parameterized according to a nonlocal K-Profile Parameterization - KPP (Large et al., 1994).

PISCES is a biogeochemical model designed to represent the first trophic levels of the marine ecosystem and the main biogeochemical cycles (Aumont et al., 2003, Aumont and Bopp, 2006). The model simulates 24 compartments. It is composed of two phytoplankton size classes (nanophytoplankton and diatoms) and two zooplankton size classes (microzooplankton and mesozooplankton). Phytoplankton growth can be limited by the availability of five different nutrients: nitrate, ammonium, phosphate, iron and silicate. Diatoms differ from nanophytoplankton by their dependence on silicate as well as by their higher half-saturation constants. The small phytoplankton size-class includes an implicit parameterization of calcite production and nitrogen fixation. PISCES also presents three non-living compartments: semi-labile dissolved organic matter (with a lifetime typically comprised of between a month and several years), small slow-sinking particles and big fast-sinking particles. The model includes the supply of nutrients to the ocean from three different sources: atmospheric deposition, river discharge and sediment mobilization (only for iron). The atmospheric dust deposition used was estimated from the monthly climatological maps simulated by Fung and Tegen (1995), assuming constant values for iron content and solubility (Tagliabue et al., 2008). The river discharges were derived from the dissolved inorganic and organic carbon discharges simulated by Ludwig et al. (1996). Carbon discharges were derived from an empirical model and were calculated as a function of a drainage intensity, basin slope and amount of carbon stored in soils. An iron flux from the continental shelf was added, with the concentrations on the shelf set to $1 \mathrm{nM}$.

As the MC is a region of high eddy activity (de Ruijter et al., 2002), it requires an eddy-resolving ocean model to capture the potential impacts of this energetic mesoscale activity on marine ecosystems. Because of the high order accuracy of ROMS numerics (allowing for enhanced effective resolution) (Shchepetkin and McWilliams, 2005), and taking into account the first 
baroclinic Rossby radius of deformation of the MC (which varies from 40-100 km from South towards the equator) (Chelton et al., 1998), a model with a horizontal resolution of $1 / 6^{\circ}(19 \mathrm{~km}$ on average for the MC) should be sufficient to accurately simulate most of the spectrum of mesoscale eddy variability (Halo et al., 2013). To keep computational costs reasonable, while preserving large scale influences, a high resolution regional model (called the child model) was nested into a larger scale model at $1 / 2^{\circ}$ resolution (called the parent model). We employed the ROMS AGRIF two-way embedding procedure, in which the parent grid provides the boundary conditions for the child grid, and where the solution of the child grid is used to improve the large scale parent grid solution (Debreu et al., 2008, 2012). Conservation of oceanic properties is enforced at the parent/child interface, allowing for long term integration (Debreu et al., 2012). The parent domain extended from $40^{\circ} \mathrm{S}-4.5^{\circ} \mathrm{N}$ and from $25.1^{\circ}-80^{\circ} \mathrm{E}$. An important point for regional ecosystem modelling is the requirement for consistency between physical and biogeochemical variables at the open boundaries. To solve this key issue, the parent model was connected for all its prognostic variables (i.e. both for the physics and for the biogeochemistry) at its lateral open boundaries to a monthly climatology, derived from a single global biogeochemical simulation based on the models NEMO and PISCES (Koné et al., 2009). The open boundary scheme is an adaptive radiation condition used in conjunction with nudging and sponge layers in the vicinity of the boundaries (Marchesiello et al., 2001). The child domain extended from $32^{\circ}-1.5^{\circ} \mathrm{S}$ and from $28^{\circ}-61^{\circ} \mathrm{E}$. Both model grids had 45 vertical levels, using the following values for vertical stretching parameters: theta $s=5.5$, theta $b=0.0$ and $h c=10 \mathrm{~m}$ (Haidvogel and Beckmann, 1999). The resulting vertical resolution ranged from 0.226-5.75 $\mathrm{m}$ for the surface layer and 1.3-594.2 $\mathrm{m}$ for the bottom layer, allowing for a proper representation of the upper ocean processes. The model topographies were derived from the $1^{\circ}$ gridded GEBCO dataset (General Bathymetric Chart of the Oceans: www.gebco.net). To prevent model errors associated with excessive slopes in iso- $\sigma$ layers, the topography (h) was smoothed in order to keep the parameter $\left(\mathrm{h}_{\mathrm{i}+1 / 2}-\mathrm{h}_{\mathrm{i}-1 / 2}\right) /\left(\mathrm{h}_{\mathrm{i}+1 / 2}+\mathrm{h}_{\mathrm{i}-1 / 2}\right)<0.2$ (Haidvogel and Beckmann, 1999).

The surface forcing fields of the models were derived from monthly climatologies following ROMSTOOLS methodology (Penven et al., 2008): Atlas of Surface Marine Data (Da Silva et al., 1994) for the heat and freshwater fluxes, QuikSCAT scatterometer observations (Liu et al., 1998) for the wind stress components, and Pathfinder sea surface temperature (SST) (Casey and Cornillon, 1994) for the correction term accounting for the SST feedback on surface heat fluxes. In addition, atmospheric dust deposition (Fung and Tegen, 1995) and dissolved inorganic and organic carbon discharges from rivers (Ludwig et al., 1996) were used for the biogeochemical model. Both model grids were initialized for January from a monthly climatology derived from the global ocean 
172 simulation (Koné et al., 2009). The simulation was run for 10 years and the outputs averaged every

1732 days. Integrated properties showed that both physical and biogeochemical models reached

174 statistical equilibrium (determined by the volume-integrated properties converging toward an equilibrium value) after 5 years (not shown). The solution was analyzed from year 6 to year 10 .

\subsection{Eddy diagnostics}

To follow variations of biogeochemical properties inside eddies during their propagation, each eddy was tracked back to its generation site. The eddy core position was identified as a local extreme in SSH (sea surface height). The eddy shape was determined using a combination of closed contours of SSH and of the Okubo-Weiss parameter as described by Halo et al. (2013). The modelled chlorophyll and nitrate concentrations were averaged over the top $10 \mathrm{~m}$ of the ocean to be consistent with SeaWiFS observations. The nitracline depth was defined at the depth of the $1 \mu \mathrm{mol} . \mathrm{L}^{-1}$ isoline. To follow variability of the nitrate supply within an eddy, new production and nitrate transport were averaged over a volume delimited on the horizontal plane by the detected eddy shape and on the vertical plane by the mixed layer. Because nitrate is the only limiting nutrient in this region (Koné et al., 2009), we have restricted our analysis to the nitrate concentrations inside eddies and the nitrate fluxes across the eddy boundaries. The nitrate fluxes were calculated from the velocity fields and the nitrate concentration and new production according to O'Niell et al. (1989).

\subsection{Data products}

Different data products were used to evaluate model performance and to define the contrasting eddy cases the model was able to simulate. They included ocean colour from SeaWiFS, altimetry from AVISO and in situ hydrological and biogeochemical observations from the CSIRO Atlas of Regional Seas (CARS). SeaWIFS weekly surface chlorophyll concentrations for the period 19982009 were used in this study. These data were produced by the NASA Goddard Space Flight Center (McClain et al., 1998). AVISO Sea Surface Height (SSH) was obtained by combining sea level anomalies derived from satellite altimetry with mean dynamic topography (Ducet and Le Traon, 2000; Le Traon et al., 2003). For temperature, salinity and nitrate data, we used annual mean fields from the CARS climatology at a spatial resolution of $1 / 2^{\circ}$, obtained from CSIRO (Commonwealth Scientific and Industrial Research Organization). CARS is an atlas derived from two major datasets interpolated onto standard depths (Dunn and Ridgway, 2002; Ridgway et al., 2002): the NODC World Ocean Atlas 1998 hydrographic data (www.nodc.noaa.gov) and the CSIRO archive of 
Australian hydrographic data.

\section{Results}

\subsection{Model behaviour}

We compared the annual mean SSH from the child domain $\left(1 / 6^{\circ}\right.$ resolution) of our modelling experiment to the AVISO SSH data (Fig. 1a, b). In both the model and observed data, a broad South Equatorial Current (SEC) flowed westward towards Madagascar between $12^{\circ} \mathrm{S}$ and $18^{\circ} \mathrm{S}$. The SEC split into two branches when it reached the coast at $17^{\circ} \mathrm{S}$. The southern branch formed the East Madagascar Current (EMC), which flows southward to become a source of the Agulhas Current (AC) after passing the southern tip of Madagascar (Schott and McCreary, 2001, DiMarco et al., 2002). The northern branch formed the Northern Madagascar Current which sweeps the northern tip of Madagascar to flow towards the African continent. It splits at the African coast at $11^{\circ} \mathrm{S}$ to form the East African Current which flows northward, and a southward branch which flows into the MC, becoming another source of the AC (Schott and McCreary, 2001, DiMarco et al., 2002). Southeast of Madagascar, the recently discovered South Indian Ocean Counter current (Palastanga et al., 2007) flowed eastward towards the centre of the Indian Ocean. The locations of these major patterns in the mean surface oceanic circulation, and mirrored in the isolines of mean $\mathrm{SSH}$, are similar in the model outputs and the observed data. However, the simulated SEC is faster than the observation, with typical velocities of the order of $35 \mathrm{~cm} \cdot \mathrm{s}^{-1}$ compared with $30 \mathrm{~cm} \cdot \mathrm{s}^{-1}$. This could be caused by a bias in the inflow provided by the global ocean model at the eastern open boundary.

In Fig. 1c, d, surface Eddy Kinetic Energy (EKE) calculated from the simulated currents was compared with EKE derived from AVISO altimetry data. EKE is the energy associated with fluctuations in the currents (after filtering out the seasonal cycle), and is a direct measure of the variability associated with eddies. The values of EKE in the central part of the MC are among the largest in the world's oceans. This is principally associated with the southward propagation of large anticyclones, in addition to oceanic turbulence at the scale of the Rossby radius of deformation (Halo et al., 2013). South of Madagascar, a secondary maximum was related to the generation of eddies and dipoles at the detachment of the EMC from the coast. In general, modeled EKE was comparable with observations (Fig. 1c, d) allowing the use of this simulation to test the effects of mesoscale turbulence on the biogeochemistry of the MC. Nevertheless, simulated levels of EKE in the northern and central MC were larger than observed. This could be related to the amplified strength of the SEC in the model, which generated larger than observed eddies with large 
241 amplitudes in the MC (Halo et al., 2013). However, this bias might also be related to the sea state

242 bias in ocean altimetry (Tran et al., 2010) or the methodologies used in the estimation of the mean

243 dynamic topography maps (Vossepoel, 2007, Maximenko et al., 2009).

245 The surface chlorophyll distributions (Fig. 2) showed characteristically low concentrations in the

246 Western Indian Ocean subtopical gyre east of Madagascar (Machu et al., 2005), high concentrations

247 in the upwelling regions on the Sofala Bank and off Somalia (Koné et al., 2009), south of

248 Madagascar (Machu et al., 2002), and along the western equatorial region, with important seasonal

249 fluctuations for the latter two. Chlorophyll a concentrations were generally lower in summer (Fig.

250 2a, c) than in winter (Fig. 2b, d). However, there was some discrepancy between the simulated and

251 observed chlorophyll concentrations. In summer, the simulated chlorophyll levels were lower than

252 the observed. The patch of high chlorophyll concentration, observed moving eastward from the

253 south of Madagascar in the summer months (Longhurst, 2001), was absent in the simulated

254 chlorophyll concentrations. In winter, the extent of the high chlorophyll patch in the Somalian

255 upwelling region was smaller than in the observed data. Chlorophyll concentrations in the

256 subtropical gyre were lower in the model compared to these observations, while in the upwelling

257 region south of Madagascar, the high levels extended further offshore than in the observed SeaWiFS

258 data. The higher values observed in the coastal zone were also absent from the simulated

259 chlorophyll concentrations. The strong simulated SEC observed at the northern tip of Madagascar

260 induced a branch of enhanced chlorophyll to the west, a feature that was absent from the

261 observations. The high chlorophyll concentrations observed in the south of the MC were

262 exaggerated in winter in the modelling experiment.

264 In order to evaluate the ability of the model to represent the vertical structure of principal oceanic

265 properties, a zonal vertical section at $24^{\circ} \mathrm{S}$ of simulated temperature, salinity and nitrate was

266 compared to CARS data (Fig. 3). Simulated temperature indicated a thermocline between $100 \mathrm{~m}$

267 and $300 \mathrm{~m}$, in agreement with observations (Fig. 3a, d). Although model surface temperatures were

268 about $2^{\circ} \mathrm{C}$ warmer than observed, the model was able to reproduce the sharp thermocline and water

269 temperature at intermediate levels. Salinity in surface waters was 35.1-35.3 (Fig. 3b, e) and

270 characterized by the presence of Tropical Surface Water (DiMarco et al., 2002). Higher salinities

271 typical of Subtropical Surface Water were present below this layer between $100 \mathrm{~m}$ and $400 \mathrm{~m}$

272 (DiMarco et al., 2002, New et al., 2007). Fresher water was located below a sharp halocline at

$273500 \mathrm{~m}$, with characteristics of the intrusion of Antarctic Intermediate Water (AAIW). AAIW is

274 characterized by salinity lower than 34.7 , and is observed between $600 \mathrm{~m}$ and $1500 \mathrm{~m}$ (DiMarco et 
al., 2002, New et al., 2007). The model was able to simulate the presence of these water masses and a strong halocline, but it underestimated the salinity maximum by 0.15 for Subtropical Surface Water and the salinity minimum by 0.125 for AAIW. This bias could be induced by diapycnal mixing or by the remote influence of global circulation which might be inaccurately reproduced at the open boundary conditions of our domain. Vertical nitrate distribution displayed a more intense gradient in our modelling experiment than in the CARS data (Fig. 3c, f respectively). However, surface layers were depleted in nitrate in the CARS observations as well as in the simulation, the nitracline being slightly shallower for the latter $(\sim 60-70 \mathrm{~m})$. Many reasons could explain the discrepancies that have been mentioned, but the model was nevertheless able to simulate the large scale patterns of regional circulation and associated biogeochemical responses, and could be used to investigate the history of mesoscale features and define their enrichment processes.

\subsection{Mesoscale eddies and biogeochemical responses}

As described above, the initial biogeochemical response to mesoscale eddy activity is chlorophyll enrichment in the core of cyclonic eddies in response to the upliftment of isopycnal surfaces bringing nutrient-rich water into the euphotic zone, and chlorophyll depletion in the centre of anticyclones resulting from the convergence and downwelling of isopycnal surfaces. However, one could easily imagine that reality is far more complex and that the observed biogeochemistry of an eddy depends on its life history (including its origin) and its interaction with other mesoscale features or with shelf regions during its lifetime. Fig. 4 presents different case studies that were investigated. In each case, the chlorophyll enrichment relative to the kind of eddy (cyclonic or anticyclonic) has been depicted as snapshots of both satellite observations and model outputs. Various contrasting case studies were specifically selected.

Two situations of surface chlorophyll concentrations associated with cyclonic eddies $(\mathrm{C} 1, \mathrm{C} 2$ and $\left.\mathrm{C} 1_{\text {obs }}, \mathrm{C} 2_{\text {obs }}\right)$ are described, one where enrichment occurs in the centre and another without noticeable enrichment. Three different signatures of surface chlorophyll enrichment associated with anticylonic eddies are then presented. $\mathrm{A} 1$ and $\mathrm{A} 1_{\mathrm{obs}}$ were anticyclones close to the coast that seemed to entrain enriched coastal waters by rotational activity. $A 2$ and $A 2_{\text {obs }}$ were anticyclones showing enrichment across the eddy, while $\mathrm{A} 3$ and $\mathrm{A} 3_{\mathrm{obs}}$ were eddies located in the middle of the $\mathrm{MC}$ containing higher chlorophyll at their periphery. The advantage of the model is that it allows a backward investigation of eddy structure as well as a study of its three-dimensional evolution. We present the life history of the eddies in these snapshots and explain why they exhibit particular 
characteristics.

\subsection{High production in a cyclonic eddy and low production in an anticyclonic eddy}

Fig. 4a, b illustrates a cyclonic eddy that is chlorophyll-enriched at its core, a case that can be explained by the eddy upwelling mechanism proposed by McGillicuddy and Robinson (1997). Cyclonic eddy $\mathrm{Cl}_{\mathrm{obs}}$ observed in the southern part of the $\mathrm{MC}$ exhibited elevated chlorophyll concentrations at its core, with values of $\sim 0.35 \mathrm{mg} \mathrm{m}^{-3}$ (Fig. 4a). In a similar feature simulated by the model (Fig. 4b), surface chlorophyll concentrations varied from $0.05-0.15 \mathrm{mg} \mathrm{m}^{-3}$. A vertical section of nitrate concentration across C1 (Fig. 5a) showed higher values in the eddy core than at the periphery in the upper $70 \mathrm{~m}$, which is the depth of the nitracline. Below the nitracline, the nitrate isolines shoaled between $39.5^{\circ} \mathrm{E}$ and $41^{\circ} \mathrm{E}$, around the core of $\mathrm{C} 1$. The vertical nitrate flux (Fig. 5b) revealed downwelling in the eddy core, with a maximum loss of nitrate of more than $0.04 \mu \mathrm{mol} \mathrm{m}{ }^{-2}$ $\mathrm{d}^{-1}$, and upwelling at the periphery that was more intense on the western side. This result appears inconsistent with the shoaling of the isolines observed in the nitrate vertical distribution. We therefore tracked the eddy back in time in order to follow the evolution of its biogeochemical characteristics prior to the snapshot shown in Fig. 4. C1 was generated south of Madagascar and propagated towards west-south-west (Fig. 5c). During the first two months, nitrate concentrations decreased steadily over time, with the core of $\mathrm{C} 1$ generally having higher levels than the surrounding waters (Fig. 5d). These nutrients sustained new production rates of $0.03 \mu \mathrm{mol} \mathrm{N} \mathrm{L}{ }^{-1} \mathrm{~d}^{-1}$ during the first phase of the eddy's life (Fig. 5f). After this initial phase of two months, the decrease in surface nitrate concentrations accelerated, resulting in a significant decline in new production and in surface chlorophyll concentrations (Fig. 5d). The decrease in surface chlorophyll commenced at the periphery of the eddy and then became noticeable within its core about two weeks later. The temporal evolution of the $\mathrm{C} 1$ amplitude showed a linear increase during the first two months after its generation (Fig. 5e). After this period the eddy appeared stable, with no significant increase in its amplitude, which then decayed a few days later. Nitrate flux through C1 (Fig. 5f) indicated that nitrate was predominantly supplied to the eddy across the vertical boundary. Maximum injection of $1 \mu \mathrm{mol} \mathrm{N} \mathrm{L} \mathrm{L}^{-1} \mathrm{~d}^{-1}$ was observed when the eddy was near its generation site south of Madagascar. Offshore, the nitrate transport was weaker and decreased with time and location towards the site of observation that was further south at $\sim 27^{\circ} \mathrm{S}$.

Anticyclone A1 (Fig. 4c, d) was observed in the central part of the MC. The eddy was depleted in chlorophyll at its centre, being $<0.1 \mathrm{mg} \mathrm{m}^{-3}$ in the SeaWiFS image and $<0.05 \mathrm{mg} \mathrm{m}^{-3}$ in the model 
343 simulation, but was enriched at its periphery. The zonal transect across A1 showed the impact of A1 344 on nitrate concentrations (Fig. 6a). The convergence at the centre of the eddy depressed the nitrate 345 isolines (deeper than $80 \mathrm{~m}$ ) and caused them to be shallower at the periphery $(50 \mathrm{~m})$. Vertical nitrate 346 fluxes (Fig. 6b) indicated weak downward fluxes in the centre and upwelling at the periphery. 347 Greater upward fluxes of nitrate were associated with the eastern edge of A1, which interacted with 348 cyclonic eddy C2 (Fig. 4d).

During its formation, A1 entrained coastal waters from the north of Madagascar (Fig. 6c). These waters were nutrient-enriched and supported new production of $\sim 0.01 \mu \mathrm{mol} \mathrm{N} \mathrm{L}{ }^{-1} \mathrm{~d}^{-1}$ (Fig. 6e). At the initial back-tracked locations in late October, a maximum in new production (Fig. 6e) was associated with elevated surface nitrate and chlorophyll (Fig. 6d), while the mixed layer was deeper (not shown). This initial nutrient input was taken up by phytoplankton as the anticyclonic eddy propagated towards the MC, without any new nutrient injection. This explained the low chlorophyll content of the eddy in February (Fig. 6d). In mid-December and mid-January, a small nitrate input produced a small peak in new production and a weak chlorophyll increase. These peaks occurred when the eddy was closest to the coast $\left(\sim 14^{\circ} \mathrm{S}\right.$ and $\left.20^{\circ} \mathrm{S}\right)$, suggesting an entrainment of surface coastal waters. Nitrate flux into eddy A1 is shown in Fig. 6e, demonstrating the dominance of vertical transport during A1's lifetime. Maximum injection of nitrate was observed in midDecember, with an injection of $0.4 \mu \mathrm{mol} \mathrm{N} \mathrm{L} \mathrm{L}^{-1} \mathrm{~d}^{-1}$, resulting in a peak in new production and

3.4. Low production in a cyclonic eddy and high production in an anticyclonic eddy

A cyclonic eddy with low chlorophyll concentration at its core was simulated by the model (C2, Fig. 4d) and a similar situation was indicated by satellite observation ( $\mathrm{C}_{\mathrm{obs}}$, Fig. 4c). The predicted nitrate distribution across C2 (Fig. 7a) showed lower concentrations at the surface everywhere within the eddy, with no significant variations between its core and its periphery. Below the surface, the nitracline was shallow at the core of the eddy at a depth of $\sim 45 \mathrm{~m}$, and deepened slightly by $\sim 5$ $\mathrm{m}$ at the periphery. This doming of the nitrate isolines was more pronounced deeper in the water column, with an upward incline of $\sim 20 \mathrm{~m}$ at $100 \mathrm{~m}$ depth. Unexpectedly, because of the doming, vertical nitrate fluxes indicated a weak downwelling in the core of the eddy. This downwelling is at its maximum at about $41.5^{\circ} \mathrm{E}$ and may explain the simulated deepening of the nitracline there. On both boundaries of $\mathrm{C} 2$, the model simulated upwelling of subsurface nitrate, being significantly stronger on the western boundary, but the nitracline gave no indication of this upwelling. 
378 The back-tracking of C2, from its location in Fig. 4d to where it was generated, is shown in Fig. 7c. This eddy was generated in the mid-MC and travelled in a westerly direction. The mean chlorophyll concentration in the eddy remained very low at $0.035 \mathrm{mg} \mathrm{m}^{-3}$ and showed no significant variation between its core and its boundaries over its tracked course (note the small values of the order of $10^{-4} \mathrm{mg} \mathrm{m}^{-3}$ in Fig. 7d). Similarly, nitrate concentrations and new production were also extremely low at $<5.5 \times 10^{-7} \mu \mathrm{mol} \mathrm{N} \mathrm{L}$ and $7 \times 10^{-7} \mu \mathrm{mol} \mathrm{N} \mathrm{L}{ }^{-1} \mathrm{~d}^{-1}$ respectively (Fig. $7 \mathrm{~d}$, e). The depths of the nitracline and chlorophyll maximum displayed similar temporal behaviour, especially for their mean values, with the chlorophyll maximum located 5-10 m below the nitracline, similar to the results for $\mathrm{C} 1$ (not shown). A comparison between the horizontal and vertical nitrate fluxes indicated a dominance of vertical injection into eddy $\mathrm{C} 2$ (Fig. 7e), with the maximum being observed from mid to late January at rates $>0.08 \mu \mathrm{molN} \mathrm{L}^{-1} \mathrm{~d}^{-1}$. Subsequently, vertical injection declined though to the end of the tracking period on 6 February 2010. The temporal evolution of new production within $\mathrm{C} 2$ displayed a slight increase with time (Fig. 7e).

SeaWiFS data indicated a productive anticyclonic eddy $\left(\mathrm{A} 2_{\mathrm{obs}}\right)$ in the $\mathrm{MC}$ where chlorophyll concentrations were $0.25 \mathrm{mg} \mathrm{m}^{-3}$ at the core (Fig. 4e). The model simulation was consistent with the observations, producing a similar productive anticyclonic eddy (A2, Fig. 4f). A vertical section across A2 revealed high nitrate concentrations at its core and decreasing towards the periphery (Fig. 8a). Instead of a deepening of the nitrate isolines at the core, and thus of the nitracline as observed in eddy A1, eddy A2 exhibited the opposite trend with relatively more elevated nitrate concentrations at the surface. The nitracline was located at $\sim 70 \mathrm{~m}$ and vertical nitrate fluxes indicated upward transport in the core and downward transport towards the boundaries of A2 (Fig. $8 b)$.

A2 was generated in the eastern MC close to Madagasgar in the vicinity of $20^{\circ} \mathrm{S}$ (Fig. 8c). From early February to mid-March, surface nitrate and chlorophyll concentrations were low (Fig. 8d). At the beginning of April, during it's southwestly propagation, A2 merged with another anticyclonic eddy generated further south (A2 ${ }^{*}$, Fig. $8 \mathrm{c}$ ). The merging of the two eddies seems to have had an impact on chlorophyll and nitrate distributions (Fig. 8d) because this period was associated with a decline in surface nitrate and chlorophyll concentrations. Chlorophyll concentrations in A2 began to increase in early May from $0.05 \mathrm{mg} \mathrm{m}^{-3}$ to reach $0.2 \mathrm{mg} \mathrm{m}^{-3}$ in the eddy core by the end of May (Fig. 8d). This corresponded to a change in the trajectory of A2 (Fig. 8c). The temporal evolution of new production closely followed the evolution of surface nitrate and chlorophyll distributions (Fig. 
411 8e), confirming an injection of nutrients during the last month of the lifetime of eddy A2. The

412 vertical and horizontal components of the nitrate fluxes within A2 (Fig. 8e) indicated the dominance of lateral nitrate transport during this month and a resulting increase in production.

\subsection{High production at the boundary of an anticyclonic eddy}

Anticyclonic eddies $\mathrm{A} 3_{\mathrm{obs}}$ and $\mathrm{A} 3$ (Fig. $4 \mathrm{~g}, \mathrm{~h}$ ) were characterized by positive sea surface height anomalies, with high chlorophyll concentrations at the boundary and decreasing towards the core. The vertical distribution of nitrate indicated higher concentrations at the core than at the periphery (Fig. 9a) and nitrate isolines were depressed at $38^{\circ} \mathrm{E}$, reflecting downward nitrate fluxes between $37^{\circ} \mathrm{E}$ and $38^{\circ} \mathrm{E}$ (Fig. 9b). Vertical nitrate fluxes on either side of the core indicated upwelling of nutrients towards the periphery of this anticyclonic eddy (Fig. 9b). Surprisingly, chlorophyll concentrations did not match the nitrate distribution, i.e. chlorophyll was not maximum at the core of the eddy where nitrate levels were highest. In this particular case, theflux core of the eddy was iron-depleted (Fig. 9f) limiting phytoplankton growth, unlike the periphery where iron concentrations were higher. This case was the only model that simulated significant iron limitation in the $\mathrm{MC}$.

Similar to A1, A3 was generated near the northeastern tip of Madagascar (Fig. 9c). The initial concentrations, as well as the supply of nitrate and iron to the surface layers, were sufficient to support new production of $\sim 0.01 \mu \mathrm{mol} \mathrm{N} \mathrm{L} \mathrm{d}^{-1}$ and maintain chlorophyll levels at $0.25-0.3 \mathrm{mg}$ $\mathrm{m}^{-3}$ (Fig. 9d, e). During the second half of August, new production increased rapidly and the concentration of chlorophyll averaged over the whole eddy was twice that at the core. This scenario was maintained until mid-September and indicated that production occurred mainly towards the boundary of the eddy. The peak in production coincided with a depletion in surface iron concentrations (Fig. 9f), ultimately resulting in chlorophyll decreasing as well (Fig. 9d). After midSeptember, the chlorophyll maximum and the nitracline deepened significantly, especially at the core of A3 (not shown). Nitrate flux over the mixed layer was characterized by a dominance of vertical injection during the early life of A3 when the eddy was near its initial location, with a maximum of about $0.4 \mu \mathrm{mol} \mathrm{N} \mathrm{L} \mathrm{d}^{-1}$ (Fig. 9e). From late July to mid-August, nitrate flux was mainly lateral, but the maximum lateral transport was $50 \%$ less than the vertical transport observed earlier in the eddy lifetime. From mid-August to the end of the simulation on 14 October 2010, maximum nitrate transport occurred across the vertical boundary at a rate of $0.3 \mu$ mol N L $\mathrm{d}^{-1}$.

444 Weak positive lateral transport was also simulated, however, and this coincided with an increase in 
iron concentration at the periphery of the eddy.

\subsection{Eddy-shelf interaction}

Model simulations of an anticyclonic eddy (A4) and a cyclonic eddy (C3) moving south and interacting with the Mozambique shelf are presented in Fig. 10a. A4 was characterized by reduced chlorophyll concentrations at its core $\left(<0.1 \mathrm{mg} \mathrm{m}^{-3}\right)$ and increasing levels towards the boundary, reaching $0.15 \mathrm{mg} \mathrm{m}^{-3}$ (Fig. 10b). On the northwestern side of this eddy, a patch of higher chlorophyll was depicted, which decreased during its southward advection. South of A4, a cyclonic eddy $\mathrm{C} 3$, located closer to the coast, was clearly identifiable by maximum chlorophyll concentrations at its core, exceeding $0.3 \mathrm{mg} \mathrm{m}^{-3}$ (Fig. 10b). The elevated chlorophyll of C3 merged with the chlorophyll plume on the southern extension of $\mathrm{A} 4\left(37^{\circ}-38^{\circ} \mathrm{E}\right)$.

The passage of eddies moving past $24^{\circ} \mathrm{S}$ are shown as time and longitude Hovmoller plots in Fig. 10c-e. Nitrate concentrations were reduced in the core of anticyclones during late February and late April, with concentrations $<0.5 \mu \mathrm{mol} \mathrm{N} \mathrm{L}{ }^{-1}$ (Fig. 10d) and resulting in low chlorophyll levels (Fig. 10e). In contrast, nitrate and chlorophyll concentrations were elevated on the southern boundaries of the anticyclones (Fig. 10c, d) and entrainment of nitrate and chlorophyll from the shelf could have contributed to these increased levels. The passage of cyclonic eddies appeared to induce an increase in nitrate up to levels $>3 \mu$ molN $\mathrm{L}^{-1}$. This suggested a shoaling of the nitracline depth to less than $50 \mathrm{~m}$ at the core of these eddies, resulting in an upliftment of nitrate into the euphotic zone. Enhanced nutrients would have induced phytoplankton growth, leading to elevated chlorophyll levels at $24^{\circ} \mathrm{S}$ as the cyclones passed by (Fig. 10e).

\section{Discussion}

The complex biophysical dynamics of the oceanic waters of the MC have been simulated using a biogeochemical model (PISCES) coupled to a hydrodynamic model (ROMS). The evaluation of model outputs indicated that the main circulation and hydrological aspects (temperature and salinity) were fairly well represented by the models, as were the distributions of nitrate and chlorophyll. The model overestimated the intensity of the SEC and winter chlorophyll concentrations, however, and also underestimated phytoplankton pigment for the summer. The discrepancy in the SEC circulation could be related to the eastern boundary conditions, while the winter overestimation of chlorophyll may be related to the non-seasonal properties of the river 
discharge of nutrients used in the simulation. A potential explanation of the underestimated chlorophyll levels during summer is the relatively coarse resolution of the model which cannot properly resolve submesoscale dynamics. In previous modelling studies, submesoscale dynamics has been shown to significantly increase primary productivity and nutrient supply in oligotrophic conditions (Lévy et al., 2001).

The model was used to study the history of eddies in the MC that displayed contrasting physical and biogeochemical characteristics, as seen in the snapshots of model outputs. We have shown that the characteristics of an eddy observed as a snapshot can be misleading, because eddies integrate several months of life history. Therefore, eddies were tracked for periods of one (C2) to four (A1, A2 ) months back in time, allowing identification of the processes responsible for enrichment in these eddies along their migratory routes.

\subsection{Importance of the origin on eddy characteristics}

Anticyclonic eddies A1, A2 and A3 that were observed in the MC showed different surface characteristics (Figs 6, 8 and 9). Intensity differed considerably between A1 and A3, both formed at the entrance of the $\mathrm{MC}\left(12^{\circ} \mathrm{S}\right)$, and $\mathrm{A} 2$, which originated to the west of Madagascar. Eddies A1 and A3 were more barotropic and energetic than eddy A2, which is consistent with their generation sites as described by Halo et al. (2013). The enrichment mechanisms varied among the eddies, with nitrate and chlorophyll concentrations in the surface layers varying by two orders of magnitude and the nitracline depth ranged from a few meters to $70 \mathrm{~m}$. Both A1 and A3 exhibited their highest nitrate concentrations in the surface layers at the location of their origin north of Madagascar, relatively close to the shelf. Despite their high energy, no additional nutrients were injected into the surface layers during their three-month passage through the MC from north to south.

For eddy A2, enrichment occurred at the end of its trajectory, when it moved closer to the shelf. This suggests that primary production in anticyclonic eddies is enhanced mainly when they interact with the coastal domain, where nutrient loading occurs as a result of river runoff, local upwelling and mixing, sediment mobilization and erosion. Such an observation supports a previous study by Whitney and Robert (2002) that indicated the role of anticyclonic eddies in the offshore transport of coastal nutrients and enhanced productivity. In all cases, the phytoplankton was sensitive to the availability of nitrate and any input to the surface layers was immediately taken up to enhance new production, as occurs in any oligotrophic area where nitrate availability limits production. 
513 Therefore, the correlation between nitracline depth, surface nitrate concentrations and net primary

514 production was strong. Among eddies we tracked, the depth of the chlorophyll maximum was often

515 located about $10 \mathrm{~m}$ below the depth of the nitracline.

517 Cyclonic eddies $\mathrm{C} 1$ and $\mathrm{C} 2$ also showed contrasting and different characteristics (Figs 5 and 7), that 518 could be explained by their different origins. C2 was formed in the central MC where oligotrophic 519 conditions prevailed at the time, with a sharp, deep nitracline and low surface nitrate concentrations.

520 During its propagation that was tracked for about one month, nothing unusual was recorded for this 521 eddy. C1 was generated at the southern tip of Madagascar, where nutrients were high because of 522 coastal upwelling. This eddy retained water properties from where it originated and displayed the 523 largest surface concentration of nitrate and the highest levels of new production of all the eddies 524 that were investigated. The initial input of nutrients maintained new production for about two 525 months, before the nitracline deepened and the nutrient supply and new production decreased in the mid-MC. Such a decrease in new production, while the amplitude of the eddy was increasing, was not consistent with the conceptual model that proposes upwelling processes in the core of cyclonic eddies (McGillicuddy and Robinson (1997). The interaction of eddies with the shelf (Fig. 10) illustrated the role of anticyclones in the offshore transport of nutrients and phytoplankton biomass from the shelf, thus enhancing open ocean productivity and corroborating previous studies by Whitney and Robert (2002) and Gruber et al. (2011).

In summary, this study established that the conceptual model described by McGillicuddy and Robinson (1997) for explaining the enrichment of eddies in subtropical regions was valid for the Mozambique Channel from a dynamical point of view. It was also demonstrated that examining the life history of an eddy is necessary for understanding the biological pattern observed in a snapshot image. The history of these structures can therefore provide valuable information for investigating the relationship between evolving eddy characteristics and the various trophic levels of the marine food web. The examples selected illustrated the complexity of the ecosystem and the importance of models for assessing details of the mechanisms responsible for primary production within eddies. The next step is to implement a study of the higher trophic levels utilising an End to End ecosystem

542 model.

\section{Acknowledgments}

547

This research was supported by the AIRD (Agence Inter-établissements de Recherche pour le Devéloppement) through its capacity building program and the LMI ICEMASA (International 
Centre for Education, Marine and Atmospheric Sciences over Africa). The MDT CNES-CLS09 data used in this work was produced by CLS Space Oceanography Division and distributed by AVISO, with support from CNES (http://www.aviso.oceanobs.com/). The topography used in the simulation of the Mozambique Channel dynamics was provided by GEBCO Digital Atlas, published on CDROM by the British Oceanographic Data Centre on behalf of the Intergovernmental Oceanographic Commission and the International Hydrographic Organization 2003. We also thank the anonymous reviewers for their valuable comments.

\section{References}

Abraham, E.R., 1998. The generation of plankton patchiness by turbulent stirring. Nature, 391, $577-580$.

Aumont, O., Bopp, L., 2006. Globalizing results from Ocean in situ iron fertilization studies. Global Biogeochem. Cycles 20, GB2017. doi:10.1029/2005GB002591.

Aumont, O., Maier-Reimer, E., Blain, S., Monfray, P., 2003. An ecosystem model of the global Ocean including $\mathrm{Fe}, \mathrm{Si}, \mathrm{P}$ colimitations. Global Biogeochem. Cycles 17. doi:10.1029/2001GB001745.

Broecker, W.S., Peng, T.H., Beng, Z., 1982. Tracers in the sea. Lamont-Doherty Geological Observatory, Palisades, New York.

Casey, K.S., Cornillon, P., 1994. A comparison of satellite and in situ based sea surface temperature climatologies. J. Climate 12, 1848-1863.

Chelton, D.B., DeSzoeke, R.A., Schlax, M.G., Naggar, K.E., Siwertz, N., 1998. Geographical variability of the first baroclinic rossby radius of deformation. J. Phys. Oceanogr. 28, 433-460.

Cotté, C., Park, Y.H., Guinet, C., Bost, C.A., 2007. Movements of foraging king penguins through marine mesoscale eddies. Proc. R. Soc. B 274, 2385-2391.

Cottin, M., Raymond, B., Kato, A., Amelineau, F., Maho, Y. L., Raclot, T., Galton-Fenzi, B., Meijers, A., Ropert-Coudert, Y., 2012. Foraging strategies of male adelie penguins during their first incubation trip in relation to environmental conditions. Mar. Biol. 159, 1843-1852.

Da Silva, A.M., Young, C.C., Levitus, S., 1994. Atlas of Surface Marine data 1994, vol. 1. Algorithms and Procedures, NOAA Atlas NESDIS 6, NOAA. Silver Spring.

de Ruijter, W.P.M., Ridderinkhof, H., Lutjeharms, J.R.E., Schouten, M.W., Veth, C., 2002. Observations of the flow in the Mozambique Channel. Geophys. Res. Lett. 29, 1401-1403.

de Ruijter, W.P.M., Ridderinkhof, H., Schouten, M.W., 2005. Variability of the southwest Indian Ocean. Phil. Trans. R. Soc. A 363, 63-76.

Debreu, L., Marchesiello, P., Penven, P., Cambon, G., 2012. Two-way nesting in split-explicit ocean models: algorithms, implementation and validation. Ocean Model. 49-50, 1-21.

Debreu, L., Vouland, C., Blayo, E., 2008. AGRIF: Adaptive grid refinement in Fortran. Comput. Geosci. 34, 8-13. 
DiMarco, S.F., Chapman, P., Jr., W.D., Hacker, P., Donohue, K., Luther, M., Johnson, G.C., Toole, J., 2002. Volume transport and property distributions of the Mozambique Channel. Deep-Sea Res. II $49,1481-1511$.

Ducet, N., Le Traon, P.Y., 2000. Global high-resolution mapping of ocean circulation from TOPEX/Poseidon and ERS1 and 2. J. Geophys. Res. 105, 19477-19498.

Dunn, J.R., Ridgway, K.R., 2002. Mapping ocean properties in regions of complex topography. Deep-Sea Res. I, 49, 591-604.

Franks, P.J.S., Wroblewski, J.S., Flierl, G.R., 1986. Prediction of phytoplankton growth in response to the frictional decay of a warm-core ring. J. Geophys. Res. 91, 7603-7610.

Fung, I., Tegen, I., 1995. Contribution to the atmospheric mineral aerosol load from land surface modification. J. Geophys. Res 18, 707-726.

Gruber, N., Lachkar, Z., Frenzel, H., Marchesiello, P., Munnich, M., McWilliams, L.C., Nagai, T., Plattner, G.K., 2011. Eddy-induced reduction of biological production in eastern boundary upwelling systems. Nat. Geosci. 4, 787-792.

Haidvogel, D.B., Beckmann, A., 1999. Numerical Ocean Circulation Modeling. Vol. 2 of Environ. Sci. Manage. 2. Imperial College Press. London.

Halo, I., Backeberg, B., Penven, P., Ansorge, C. R. I., Ulgren, J., 2013. Eddy properties in the Mozambique Channel: A comparison between satellite altimetry and Ocean Circulation models. Deep-Sea Res. II

Haney, J.C., 1986. Seabird Patchiness in Tropical Oceanic Waters: The influence of Sargassum "Reefs". The Aku 103, 141-151.

Huggett, J.A., 2013. Mesoscale distribution and community composition of zooplankton in the Mozambique Channel. Deep-Sea Res. II

Kishi, M., 1994. Prediction of Phytoplankton Growth in a Warm-Core Ring Using Three Dimensional Ecosystem Model. J. Oceanogr. 50, 489-498.

Koné, V., Aumont, O., Levy, M., Resplandy, L., 2009. Physical and biogeochemical controls of the phytoplankton seasonal cycle in the Indian Ocean: A modelling study. Geophys. Monogr. Ser. 185, $147-166$.

Large, W.G., McWilliams, J.C., Doney, S.C., 1994. Oceanic vertical mixing: A review and a model with a nonlocal boundary layer parameterization. J. Geophys. Res. 32, 363-403.

Le Traon, P.Y., Faugere, Y., Hernandez, F., Dorandeu, J., Mertz, F., Ablain, M., 2003. Can We Merge GEOSAT Follow-On with TOPEX/Poseidon and ERS-2 for an Improved Description of the Ocean Circulation? J. Atmos. Oceanic Technol. 20, 889-895.

Lebourges-Dhaussy, A., Huggett, J., Ockhuis, S., Roudaut, G., Josse, E., Verheye, H., 2013. Zooplankton size and distribution within mesoscale structures in the Mozambique Channel: a 
comparative approach using the TAPS acoustic profiler, a multiple net sampler and ZooScan image analysis. Deep-Sea Res. II

Legendre, L., Rassoulzadegan, F., 1995. Plankton and nutrient dynamics in marine waters. Ophelia 41, 153-172.

Lévy, M., Ferrari, R., Franks, P.J.S., Martin, A.P., Riviére, P., 2012. Bringing physics to life at the submesoscale. Deep-Sea Res. I 39, 1-13.

Lévy, M., Klein, P., Treguier, A.M., 2001. Impact of sub-mesoscale physics on production and subduction of phytoplankton in an oligotrophic regime. J. Mar. Res. 59, 535-565.

Liu, W.T., Tang, W., Polito, P.S., 1998. NASA scatterometer provides global ocean-surface wind fields with more structures than numerical weather prediction. Geophys. Res. Lett. 25, 761-764.

Longhurst, A., 2001. A major seasonal phytoplankton bloom in the Madagascar Basin. Deep-Sea Res. I 48, 2413-2422.

Ludwig, W., Probst, J., Kempe, S., 1996. Predicting the oceanic input of organic carbon by continental erosion. Global Biogeochem. Cycles 10, 23-41.

Machu, E., Biastoch, A., Oschlies, A., Kawamiya, M., Lutjeharms, J.R.E., Garon, V., 2005. Phytoplankton distribution in the Agulhas system from a coupled physical biological model. DeepSea Res. I 52, 1300-1318.

Machu, E., Lutjeharms, J.R.E., Webb, A.M., Aken, H. M. V., 2002. First hydrographic evidence of the southeast Madagascar upwelling cell. Geophysi. Res. Lett. 29, 1-5.

Marchesiello, P., McWilliams, J.C., Shchepetkin, A., 2001. Open boundary conditions for long-term integration of regional oceanic models. Ocean Model. 3, 1-20.

Maximenko, N., Niiler, P., Melnichenko, M.H.R.O., Centurioni, L., Chambers, D., Zlotnicki, V., Galperin, B., 2009. Mean dynamic topography of the ocean derived from satellite and drifting buoy data using three different techniques. J. Atmos. Oceanic Technol. 26, 1911-1919.

McClain, C.R., Cleave, M.L., Feldman, G.C., Gregg, W.W., Hooker, S.B., Kuring, N., 1998. Science Quality SeaWiFS Data for Global Biosphere Research. Sea Technol. 10-16.

McGillicuddy, D.J., Robinson, A.R., 1997. Eddy-induced nutrient supply and new production in the Sargasso Sea. Deep-Sea Res. I 44, 1427-1450.

Nel, D.C., Lutjeharms, J.R.E., Pakhomov, E.A., Ansorge, I.J., Ryan, P.G., Klages, N.T.W., 2001. Exploitation of mesoscale oceanographic features by grey-headed albatross thalassarche chrysostoma in the southern Indian Ocean. Mar. Ecol. Prog. Ser. 217, 15-26.

New, A.L., Alderson, S.G., Smeed, D.A., Stansfield, K.L., 2007. On the circulation of water masses across the Mascarene Plateau in the South Indian Ocean. Deep-Sea Res. I 54, 42-74.

O'Niell, R.V., DeAngelis, D.L., Pastor, J.J., Jackson, B.J., Post W.M., 1989. Multiple nutrient limitations in ecological models. Ecol. Model. 46. 147-163. 
Oschlies, A., Garcon, V., 1998. Eddy-induce enhancement of primary production in a model of the North Atlantic Ocean. Nature 394, 266-269.

Palastanga, V., van Leeuwen, P.J., Schouten, M.W., de Ruijter, W.P.M., 2007. Flow structure and variability in the Subtropical Indian Ocean: Instability of the South Indian Ocean Countercurrent. J.Geophys. Res. 112, 1-11.

Penven, P., Marchesiello, P., Debreu, L., Lefevre, L., 2008. Software tools for pre and postprocessing of oceanic regional simulations. Environ. Model. Softw. 23, 660-662.

Quartly, G.D., Srokosz, M.A., 2003. A plankton guide to ocean physics: colouring in the currents around South Africa and Madagascar. Ocean Challenge 12, 19-23.

Ridgway, K.R., Dunn, J.R., Wilkin, J.L., 2002. Ocean interpolation by four dimensional weighted least Squares-Application to the waters around Australasia. J. Atmos. Oceanic Technol. 19, 13571375.

Sarmiento, J.L., Gruber, N., 2006. Ocean Biogeochemical Dynamics. Princeton Univeresity Press. Princeton.

Scheffer, A., Trathan, P. N., Collins, M., 2010. Foraging behaviour of King Penguins (Aptenodytes patagonicus) in relation to predictable mesoscale oceanographic features in the Polar Front Zone to the north of South Georgia. Prog. Oceanogr. 86, 232-245.

Schott, F.A., McCreary, J.P., 2001. The monsoon circulation of the Indian Ocean. Prog. Oceanogr. $51,1-123$.

Schouten, M.W., de Ruijter, A.P.M., van Leeuwen, P.J., Ridderinkhof, H., 2003. Eddies and variability in the Mozambique Channel. Deep-Sea Res. II 50, 1987-2003.

Shchepetkin, A.F., McWilliams, J.C., 2005. The regional oceanic modeling system (ROMS): a splitexplicit, free-surface, topography-following-coordinate oceanic model. Ocean Model. 9, 347-404.

Tagliabue, A., Bopp, L., Aumont, O., 2008. Ocean biogeochemistry exhibits contrasting responses to a large scale reduction in dust deposition. Biogeosci. 5, 11-24.

Tew-Kai, E., Marsac, F., 2010. Influence of mesoscale eddies on spatial structuring of top predators' communities in the Mozambique Channel. Prog. Oceanog. 86, 214-223.

Tran, N., Vandemark, D., Labroue, S., Feng, H., Chapron, B., Tolman, H.L., Lambin, J., Picot, N., 2010. Sea state bias in altimeter sea level estimates determined by combining wave model and satellite data. J. Geophys. Res. 115, 1-7.

Valiela, I., 1995. Marine Ecological Processes. Springer Verlag, New York.

Vossepoel, F.C., 2007. Uncertainties in the mean ocean dynamic topography before the launch of the gravity field and steady-state ocean circulation explorer (GOCE). J. Geophys. Res. 112, 1-20.

Waite, A., Thompson, P., Pesant, S., Feng, M., Beckley, L., Domingues, C., Gaughan, D., Hanson, 
C., Holl, C., Koslow, T., Meuleners, M., Montoya, J., Moore, T., Muhling, B., Paterson, H., Rennie, S., Strzelecki, J., Twomey, L., 2007. The Leeuwin Current and its eddies: An introductory overview.

Weimerskirch, H., 2007. Are seabirds foraging for unpredictable resources? Deep-Sea Res. II 54, 211-223.

Weimerskirch, H., Corre, M. L., Jaquemet, S., Potier, M., Marsac, F., 2004. Foraging strategy of a top predator in tropical waters: great frigatebirds in the Mozambique Channel. Mar. Ecol. 275, 297308.

Whitney, F., Robert, M., 2002. Structure of Haida eddies and their transport of nutrient from coastal margins into the NE Pacific Ocean. J. Oceanogr. 58, 715-723.

Williams, R.G., Follows, M.J., 1998. The Ekman transfer of nutrients and maintenance of new production over the North Atlantic. Deep-Sea Res. I 45, 461-489.

Yentsch, C.S., Phinney, D.A., 1985. Rotary motions and convection as a means of regulating primary production in warm core rings. J. Geophys. Res. 90, 3237-3248.

\section{Figure legends}

Fig. 1. Annual mean SSH (10 cm) for (a) ROMS and (b) AVISO altimetry, and annual mean EKE $\left(10^{2} \mathrm{~cm}^{2} \mathrm{~s}^{-2}\right)$ for (c) ROMS and (d) AVISO altimetry.

Fig. 2. Sea surface chlorophyll concentration $\left(\mathrm{mg} \mathrm{Chl} \mathrm{m}^{-3}\right)$ in $(\mathrm{a}, \mathrm{c})$ summer (January, February, March) and in (b, d) winter (July, August, September) for (a, b) model simulation and (c, d) SeaWIFS observations.

Fig. 3. Vertical distribution of (a, d) annual mean temperature $\left({ }^{\circ} \mathrm{C}\right),(\mathrm{b}, \mathrm{e})$ salinity, and $(\mathrm{c}, \mathrm{f})$ nitrate concentration $\left(\mu \mathrm{mol} \mathrm{N} \mathrm{L}^{-1}\right)$ at $24^{\circ} \mathrm{S}$ for (a-c) model simulation and (d-f) CARS climatology.

Fig. 4. Surface chlorophyll concentration (Chla, in colour, $\mathrm{mg} \mathrm{m}^{-3}$ ) and superimposed sea surface height anomaly (SLA, contours, cm) for various mesoscale eddies in the Mozambique Channel. Left panels are SeaWiFS and AVISO observations (obs) and right panels are model outputs. Bold lines indicate positive anomalies and thin lines are negative anomalies. $\mathrm{C} 1_{\text {obs }}: 15$ and 16 July 2003 for SLA and Chla respectively; C1: average for 6-12 November, year 8; A1 $1_{\text {obs: }} 16$ and 17 April 2008 for SLA and Chla respectively; A1: average for 4-6 February, year 10; C2 obs: 16 and 17 April 2008 for SLA and Chla respectively; C2: average for 4-6 February, year 10); A2 obs: 27 and 28 May 2009 for SLA and Chla respectively; A2: average for 20-26 May, year 9; A3 obs: 28 January 2004 for both SLA and Chla; A3: average for 12-14 October, year 10.

Fig. 5. Vertical sections across $\mathrm{C} 1$ (Fig. 4b) for (a) nitrate concentrations ( $\mu \mathrm{mol} \mathrm{N} \mathrm{L}{ }^{-1}$ ), (b) vertical nitrate flux ( $\mu \mathrm{mol} \mathrm{N} \mathrm{m} \mathrm{N}^{-2} \mathrm{~s}^{-1}$ ), (c) evolution of the centre of $\mathrm{C} 1$ tracked back in time, (d) chlorophyll and nitrate concentrations averaged over the upper $10 \mathrm{~m}$, (e) $\mathrm{C} 1$ amplitude along the time track, and (f) nitrate fluxes and new production averaged over the mixed layer. Shading and negative values in (b) indicates downward fluxes. Bold and dashed lines in (f) indicate horizontal and vertical nitrate fluxes.

Fig. 6. Vertical sections across A1 (Fig. 4d) for (a) nitrate concentrations ( $\mu$ mol N L-1), (b) vertical 
nitrate flux ( $\mu \mathrm{mol} \mathrm{N} \mathrm{m} \mathrm{m}^{-2} \mathrm{~s}^{-1}$ ), (c) evolution of the centre of A1 tracked back in time, (d) chlorophyll and nitrate concentrations averaged over the upper $10 \mathrm{~m}$, and (e) nitrate fluxes and new production averaged over the mixed layer. Shading and negative values in (b) indicates downward fluxes. Bold and dashed lines in (e) indicate horizontal and vertical nitrate fluxes.

Fig. 7. Vertical sections across C2 (Fig. 4d) for (a) nitrate concentrations ( $\mu \mathrm{mol} \mathrm{N} \mathrm{L}{ }^{-1}$ ), (b) vertical nitrate flux ( $\mu \mathrm{mol} \mathrm{N} \mathrm{m} \mathrm{s}^{-1}$ ), (c) evolution of the centre of $\mathrm{C} 2$ tracked back in time, (d) chlorophyll and nitrate concentrations averaged over the upper $10 \mathrm{~m}$, and (e) nitrate fluxes and new production averaged over the mixed layer. Shading and negative values in (b) indicates downward fluxes. Bold and dashed lines in (e) indicate horizontal and vertical nitrate fluxes.

Fig. 8. Vertical sections across A2 (Fig. 4f) for (a) nitrate concentrations ( $\mu \mathrm{mol} \mathrm{N} \mathrm{L}^{-1}$ ), (b) vertical nitrate flux ( $\mu \mathrm{mol} \mathrm{N} \mathrm{m} \mathrm{s}^{-1}$ ), (c) evolution of the centre of $\mathrm{A} 2$ tracked back in time, (d) chlorophyll and nitrate concentrations averaged over the upper $10 \mathrm{~m}$, and (e) nitrate fluxes and new production averaged over the mixed layer. Shading and negative values in (b) indicates downward fluxes. Bold and dashed lines in (e) indicate horizontal and vertical nitrate fluxes.

Fig. 9. Vertical sections across A3 (Fig. 4h) for (a) nitrate concentrations ( $\mu \mathrm{mol} \mathrm{N} \mathrm{L}{ }^{-1}$ ), (b) vertical nitrate flux ( $\mu \mathrm{mol} \mathrm{N} \mathrm{m} \mathrm{s}^{-2}$ ), (c) evolution of the centre of A3 tracked back in time, (d) chlorophyll and nitrate concentrations averaged over the upper $10 \mathrm{~m}$, (e) nitrate fluxes and new production averaged over the mixed layer, and (f) iron concentrations. Shading and negative values in (b) indicates downward fluxes. Bold and dashed lines in (e) indicate horizontal and vertical nitrate fluxes.

Fig. 10. Model simulations of an anticyclonic eddy (A4) and a cyclonic eddy (C3) interacting with the shelf for (a) sea surface height anomalies (cm) (8 April, year 10) and (b) chlorophyll concentrations $\left(\mathrm{mg} \mathrm{m}^{-3}\right)$ averaged over the upper $10 \mathrm{~m}$. The passage of eddies moving past $24^{\circ} \mathrm{S}$ are shown as time and longitude Hovmoller plots for (c) sea surface height anomalies $(\mathrm{cm})$, (d) nitrate concentrations ( $\mu \mathrm{mol} \mathrm{N} \mathrm{L}^{-1}$ ) at $50 \mathrm{~m}$, and (e) chlorophyll concentrations $\left(\mathrm{mg} \mathrm{m}^{-3}\right.$ ) at $50 \mathrm{~m}$. Shading in (c) indicates negative anomalies. 

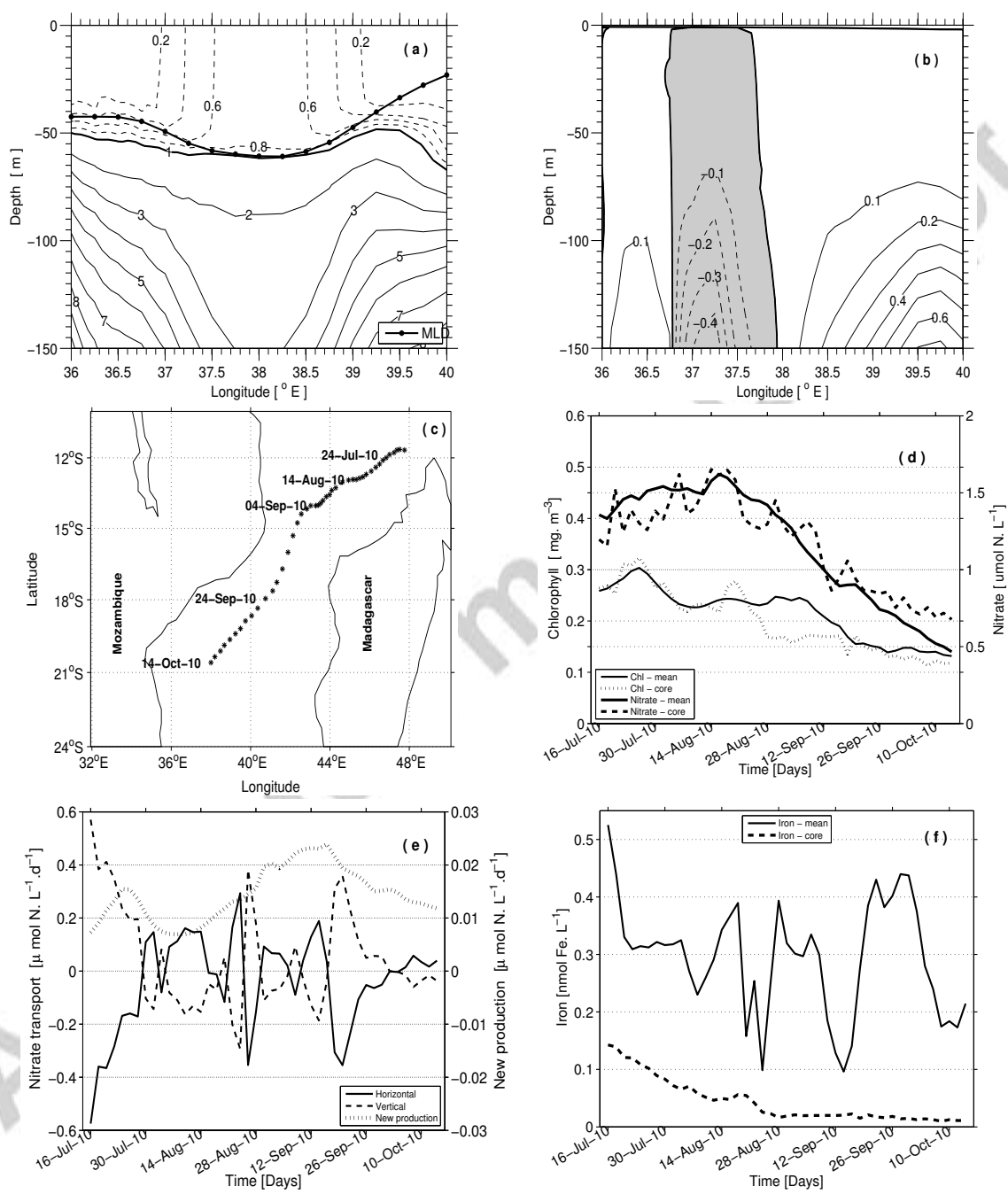

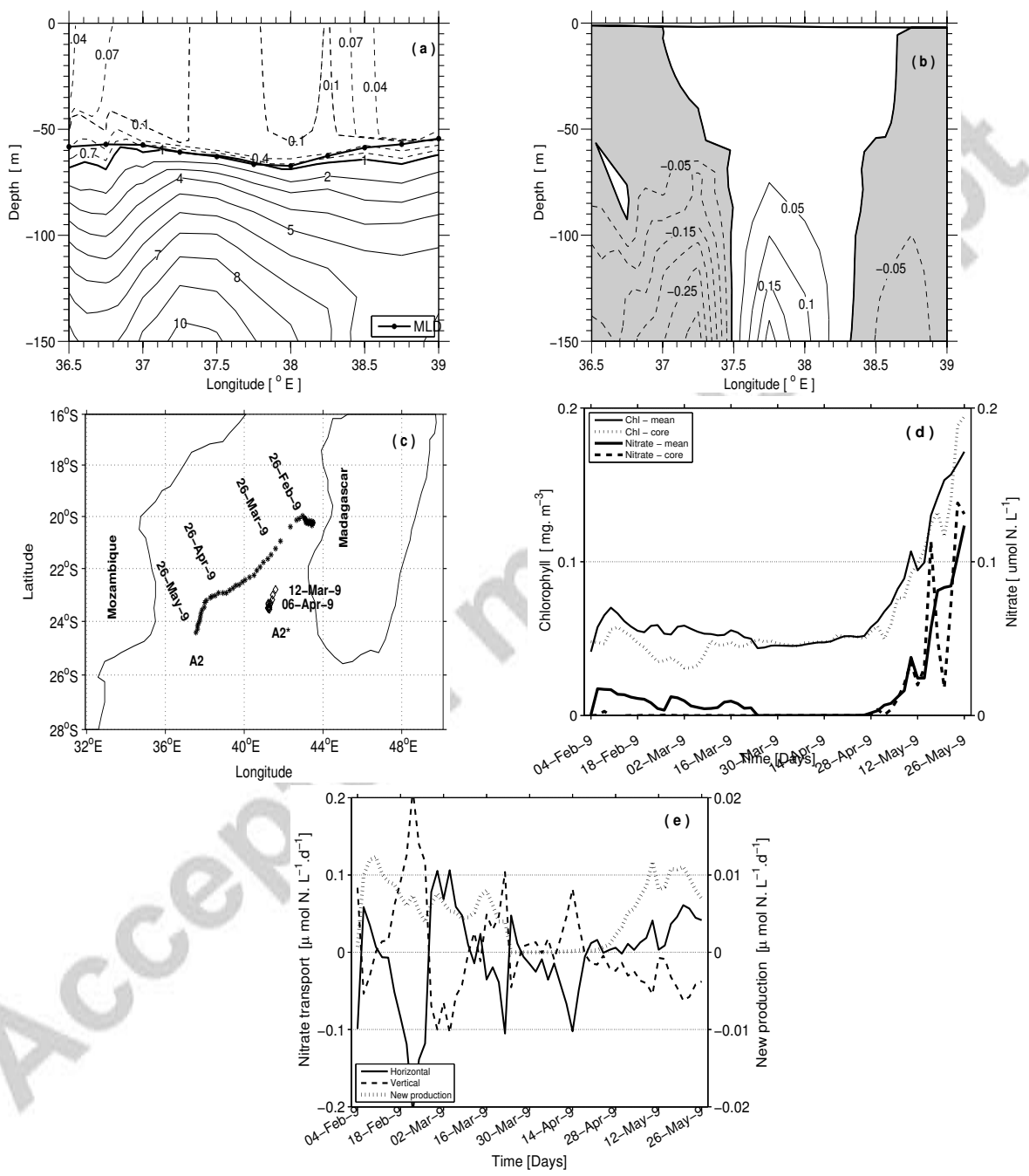

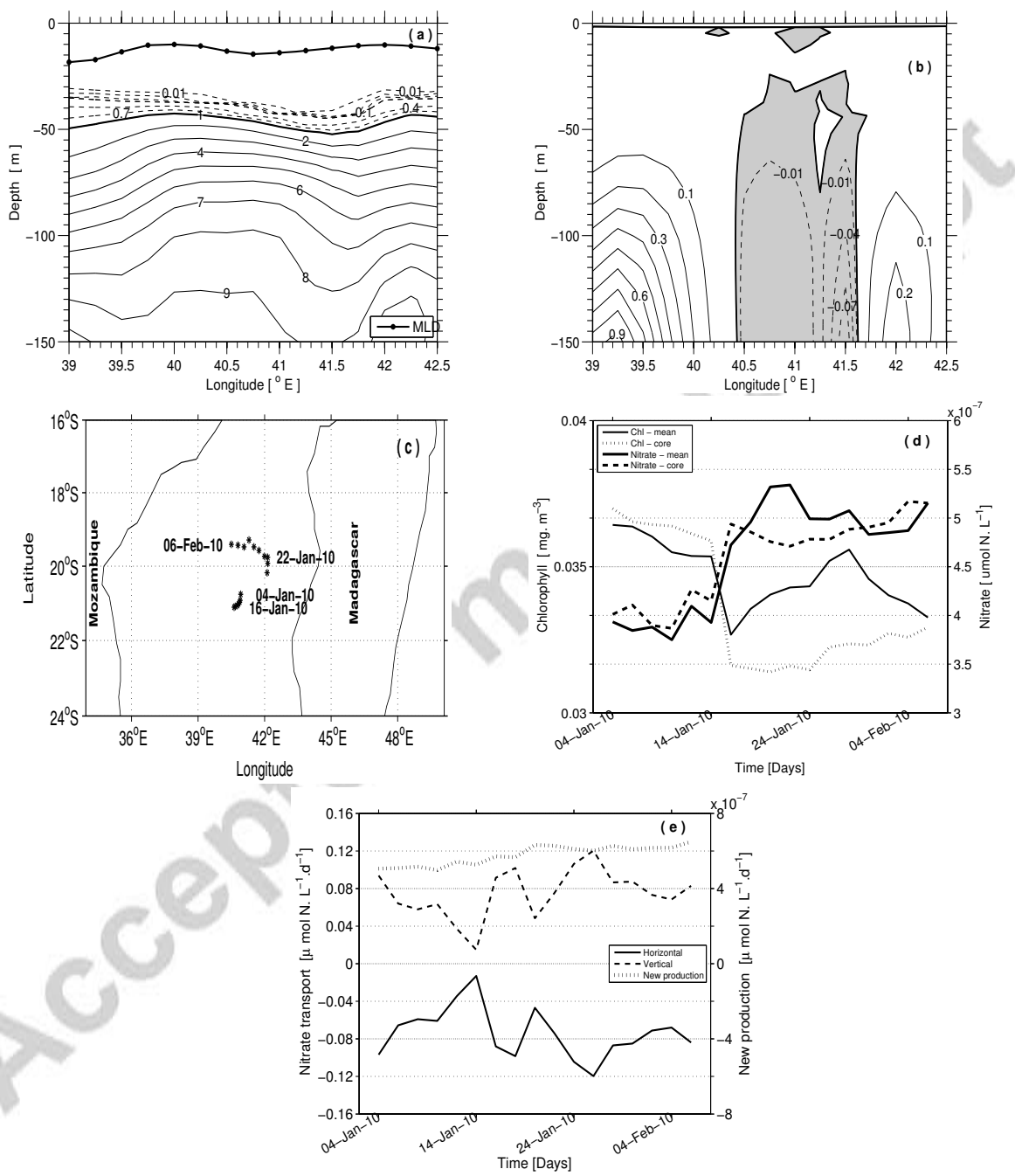

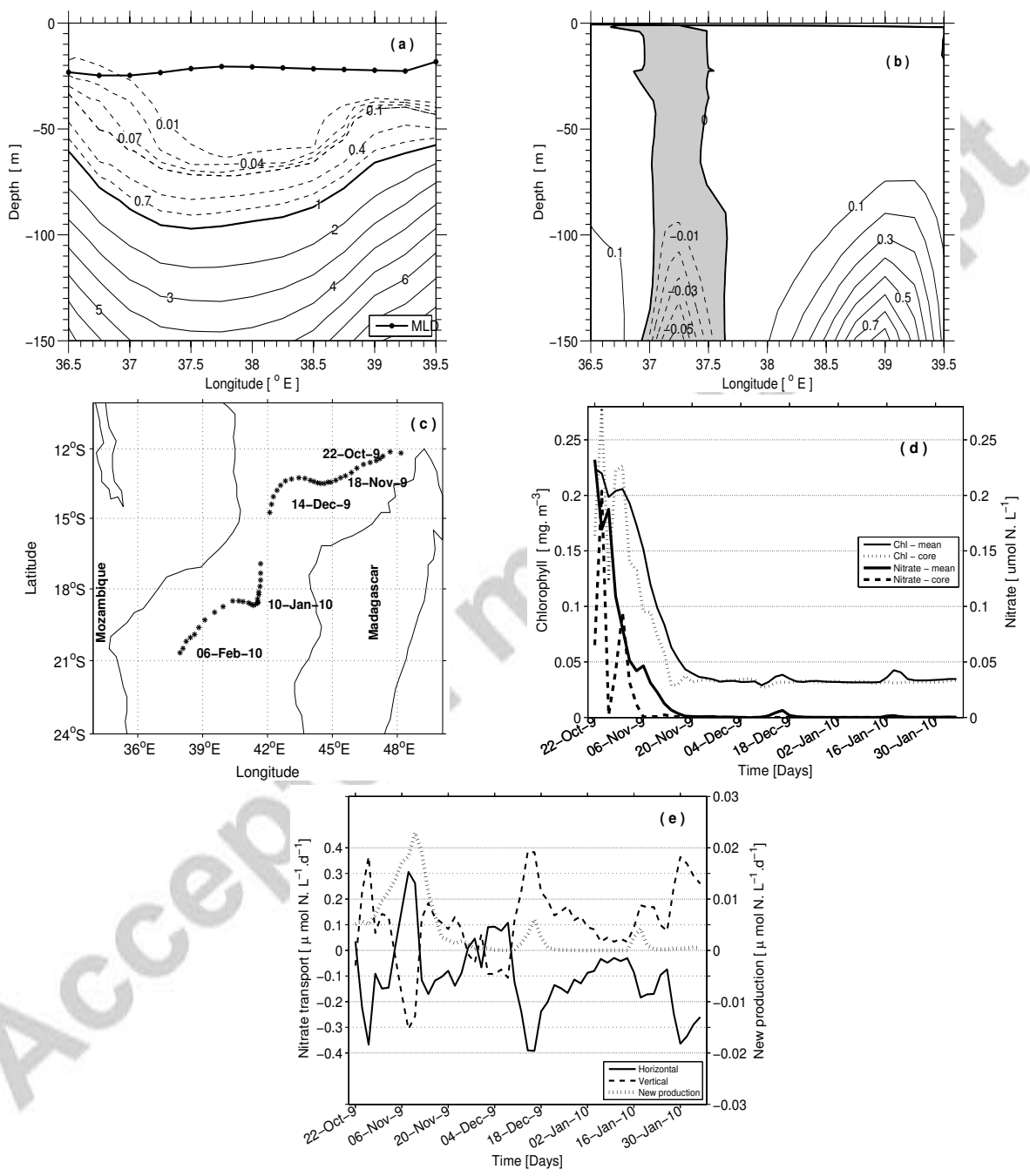

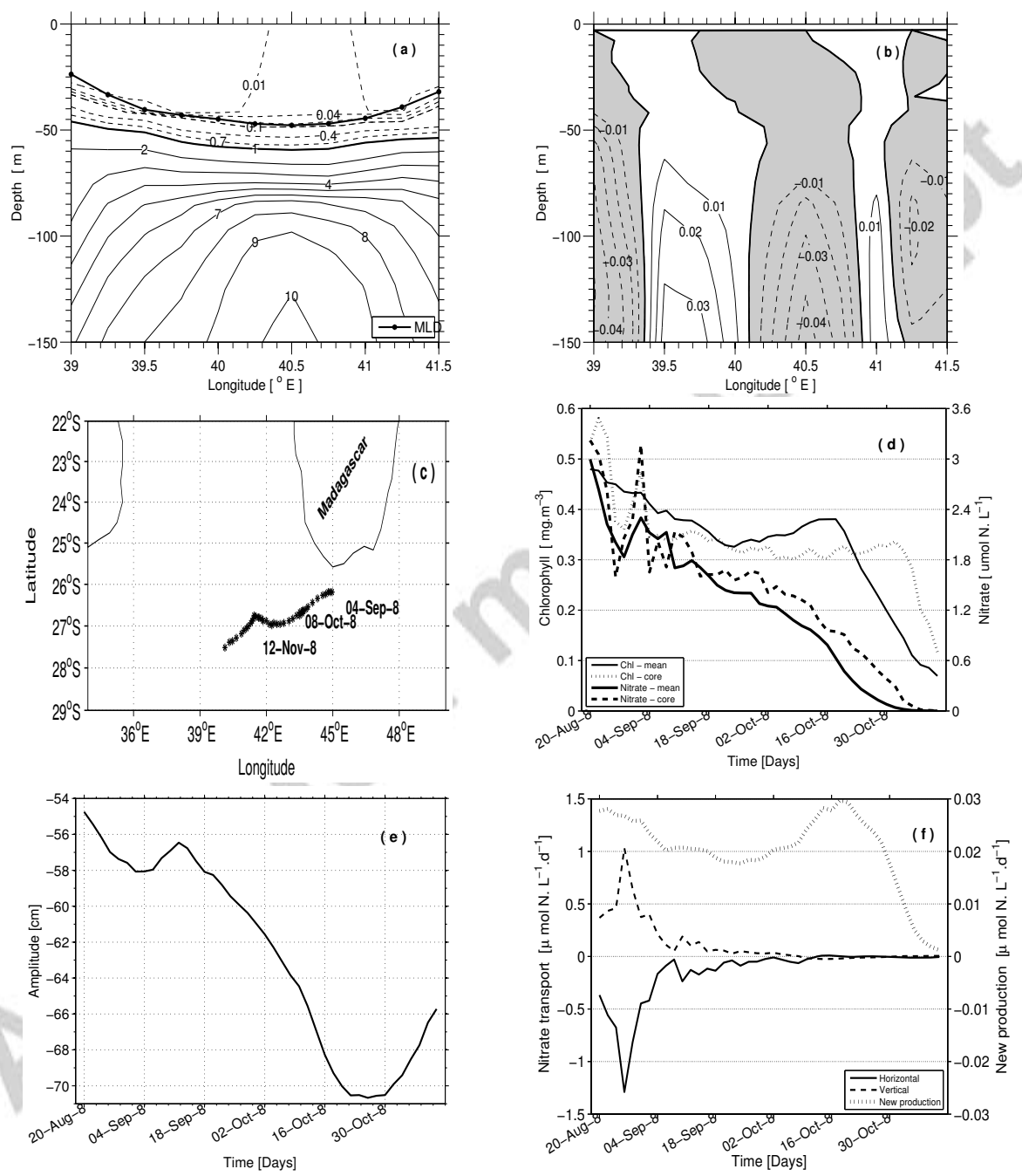

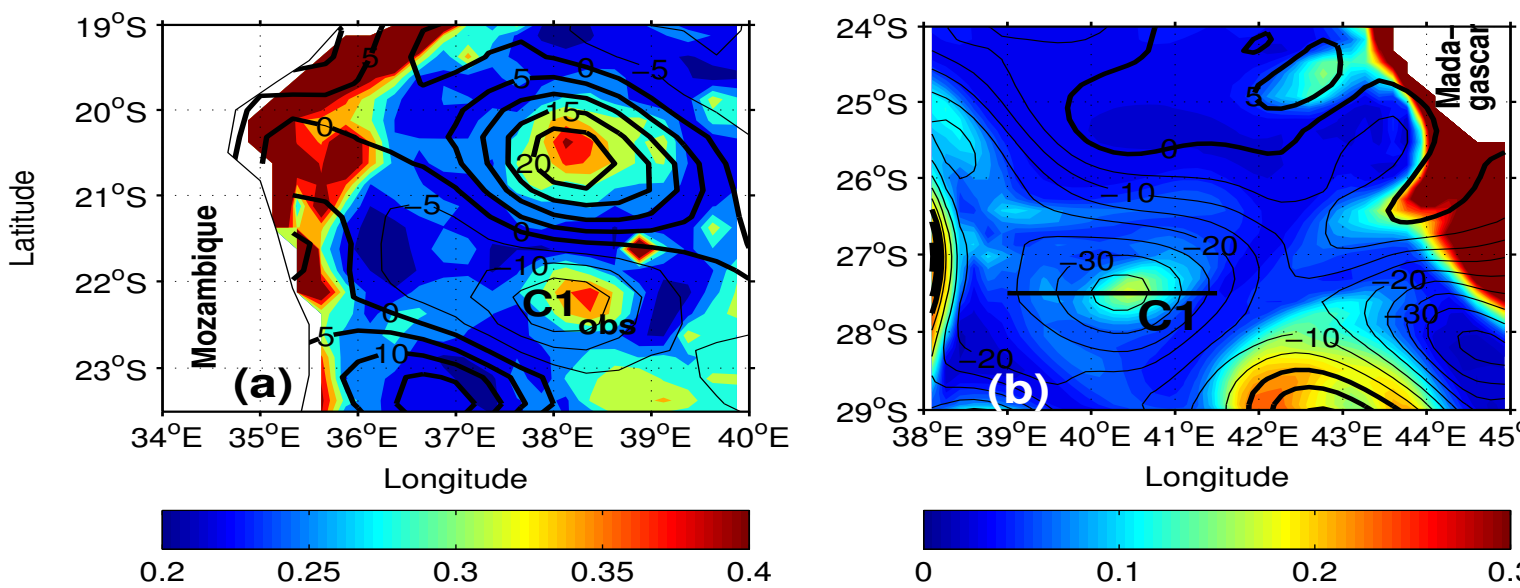

$38^{\circ} \mathrm{E} 39^{\circ} \mathrm{E} 40^{\circ} \mathrm{E} 41^{\circ} \mathrm{E} 42^{\circ} \mathrm{E} 43^{\circ} \mathrm{E} 44^{\circ} \mathrm{E} 45^{\circ} \mathrm{E}$ Longitude
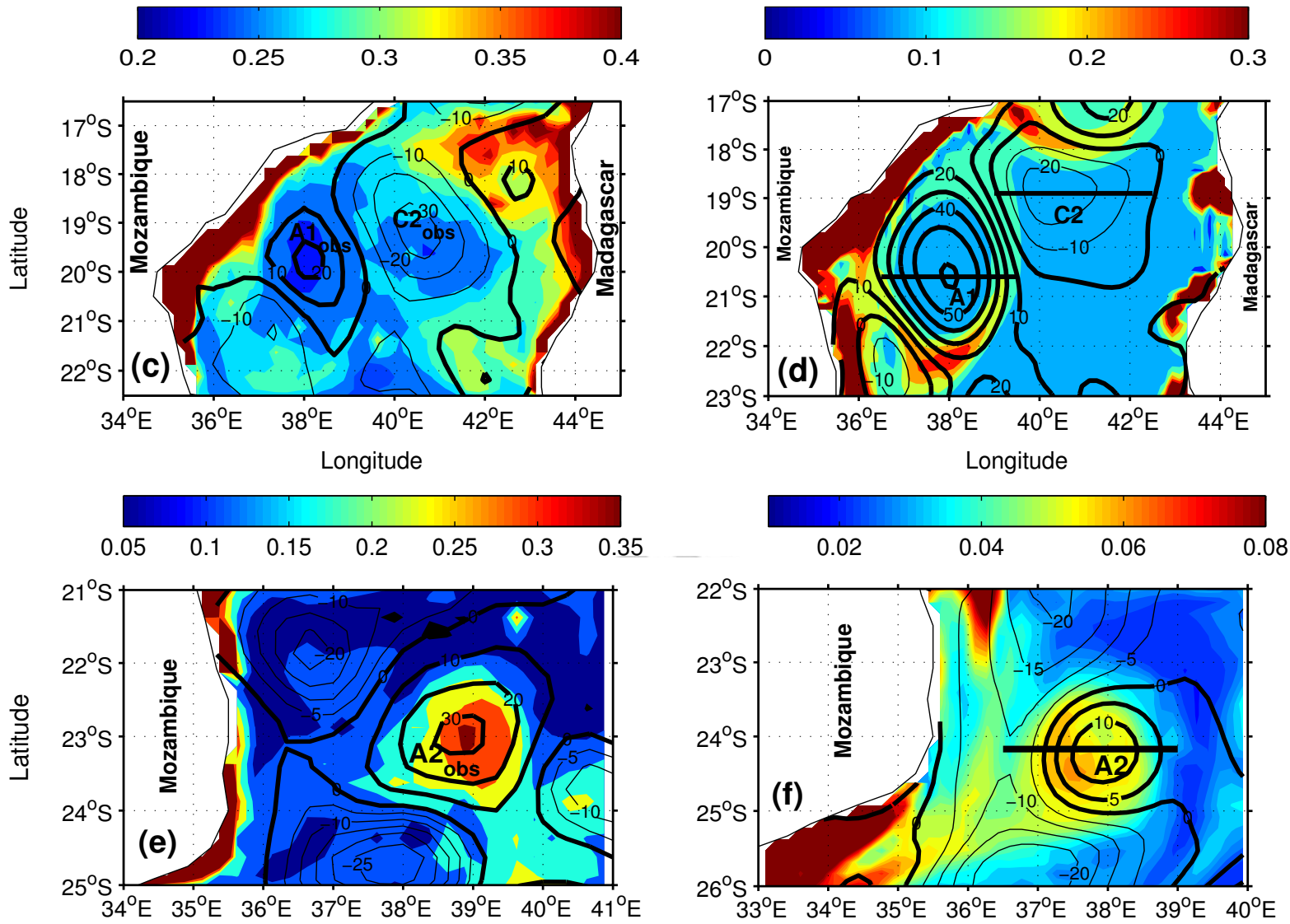

Longitude
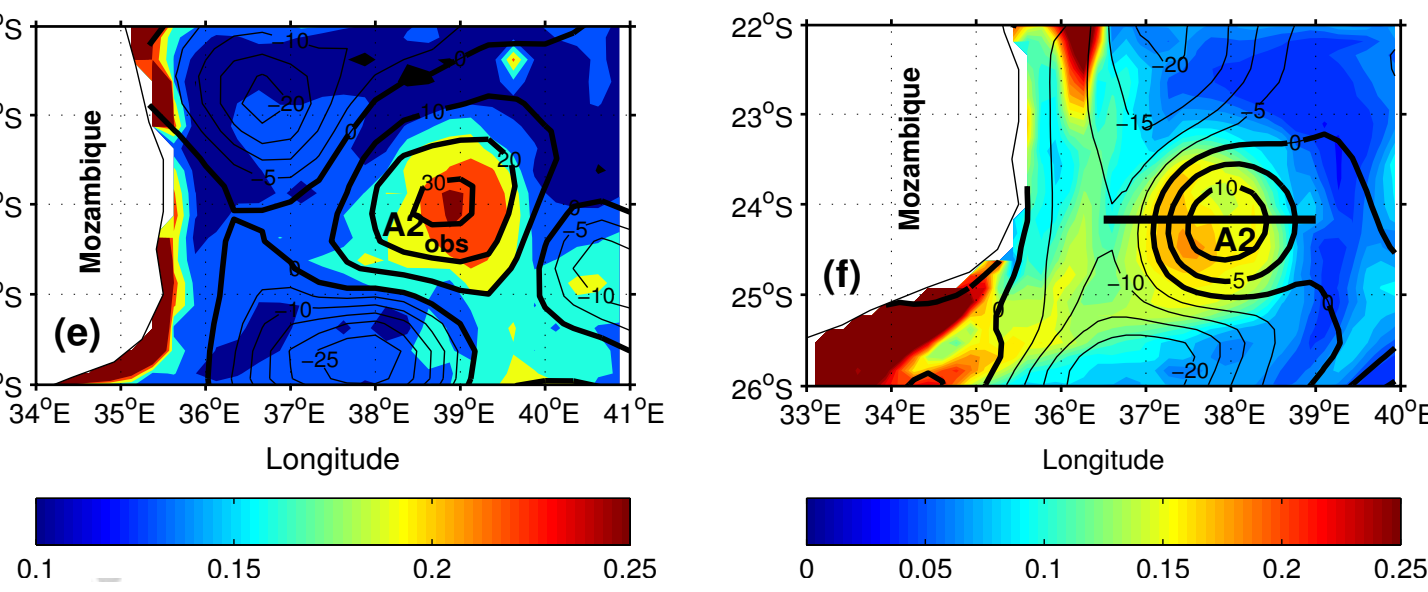

$\begin{array}{llllllllll}33^{\circ} \mathrm{E} & 34^{\circ} \mathrm{E} & 35^{\circ} \mathrm{E} & 36^{\circ} \mathrm{E} & 37^{\circ} \mathrm{E} & 38^{\circ} \mathrm{E} & 39^{\circ} \mathrm{E} & 40^{\circ} \mathrm{E}\end{array}$ Longitude
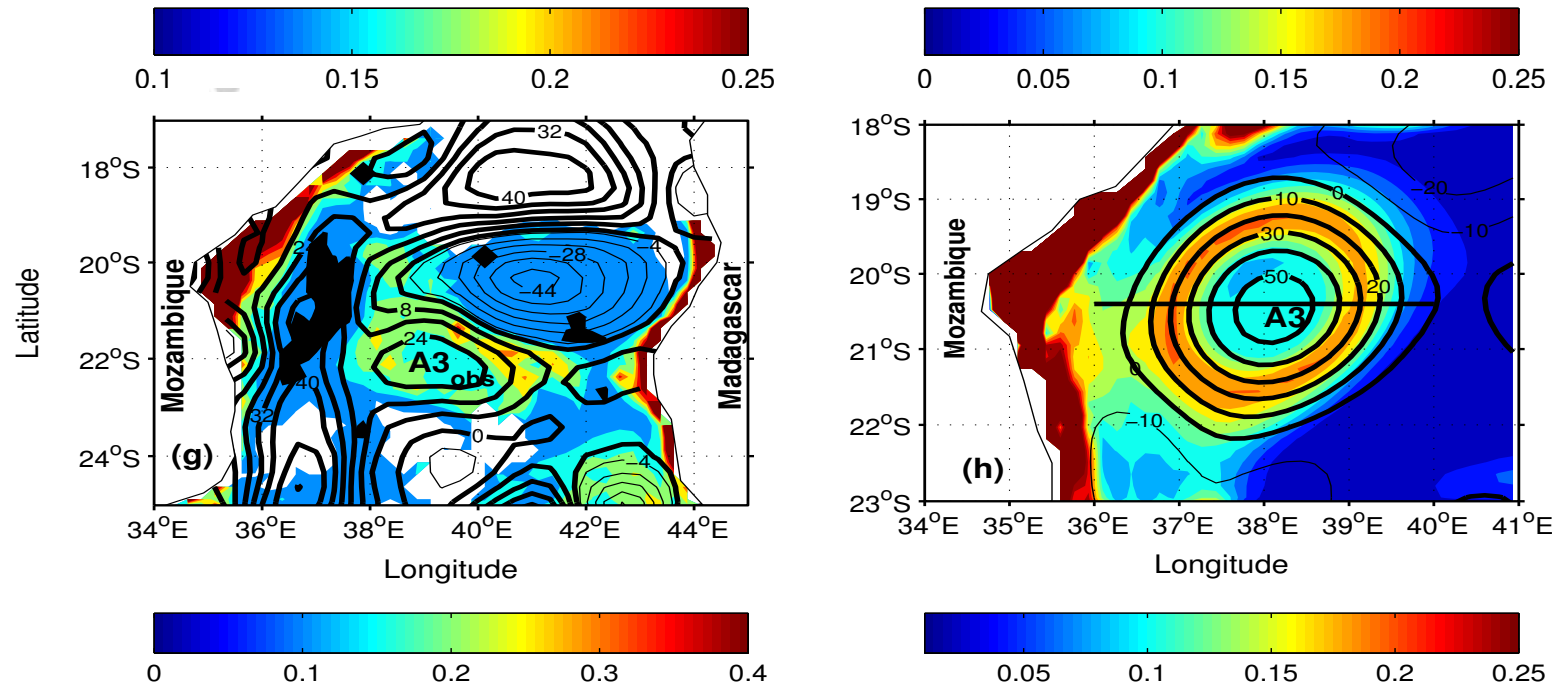


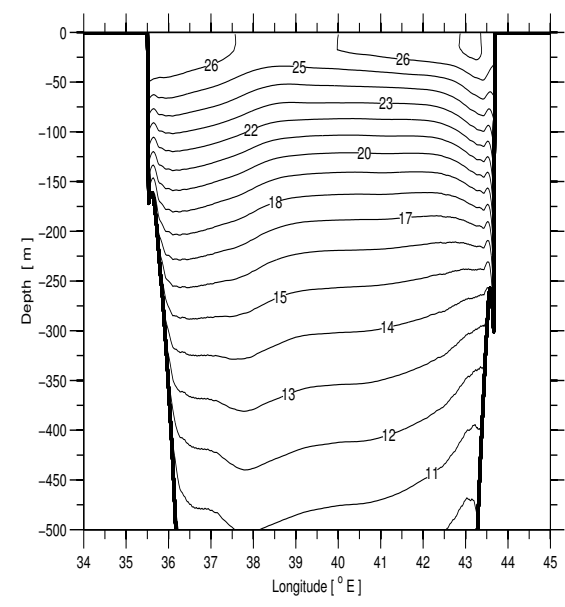

(a)

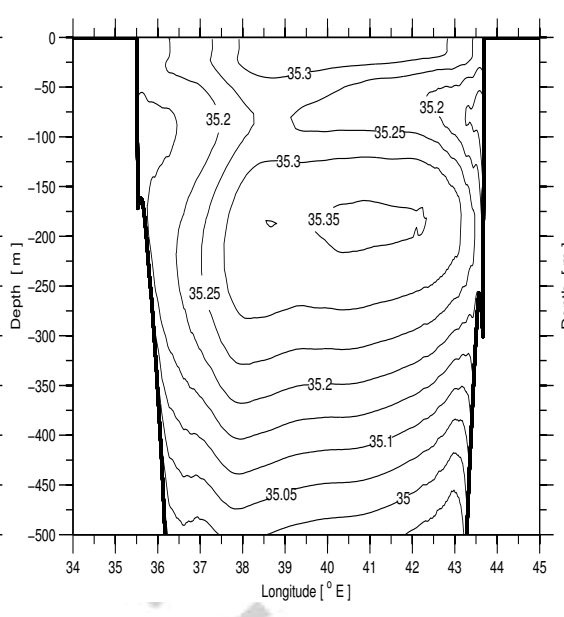

(b)

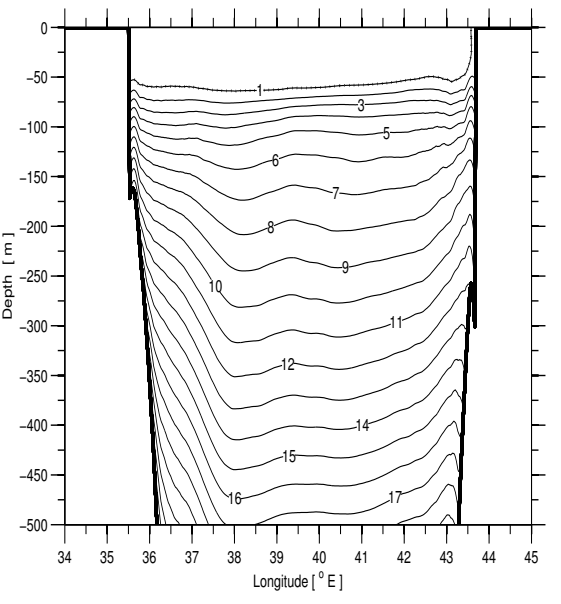

(c)

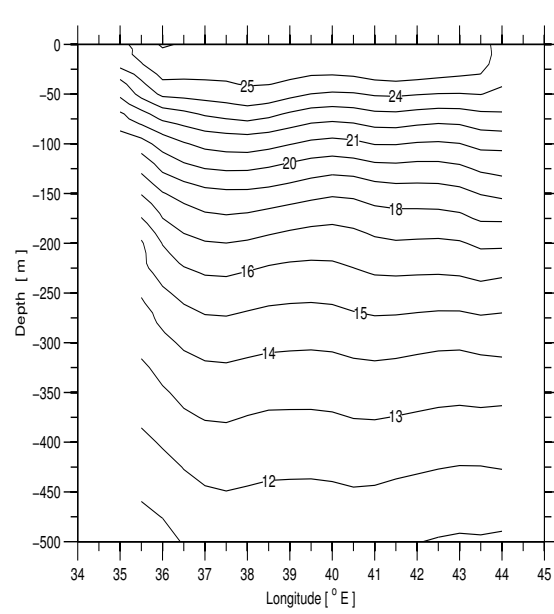

(d)

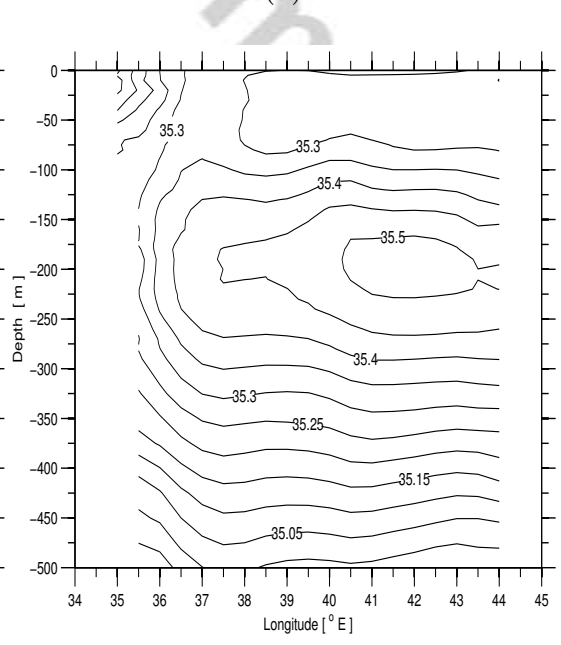

(e)

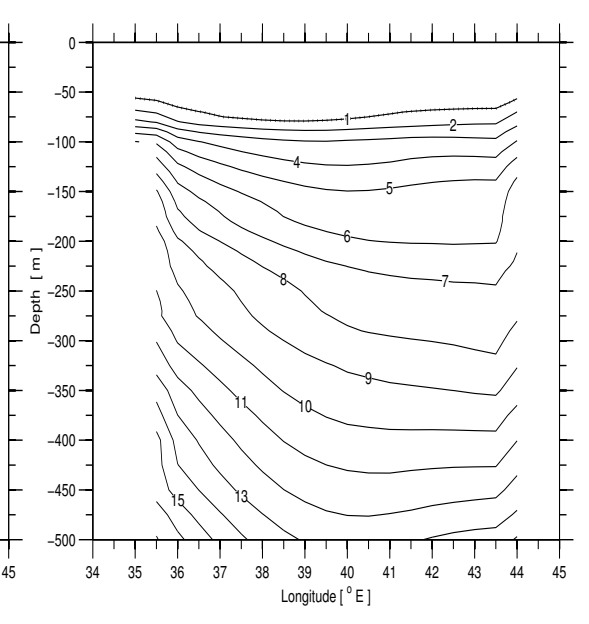

(f) 

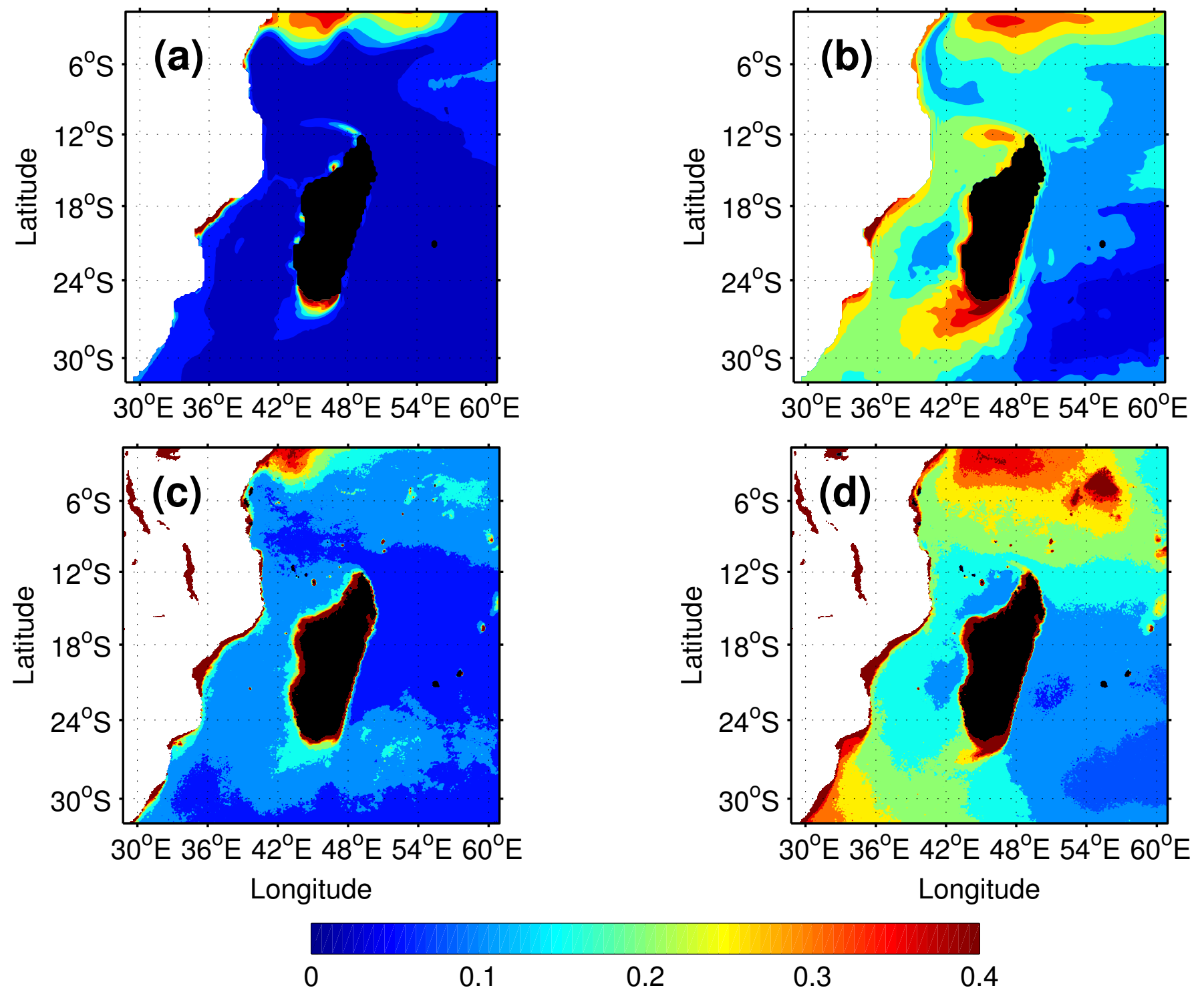

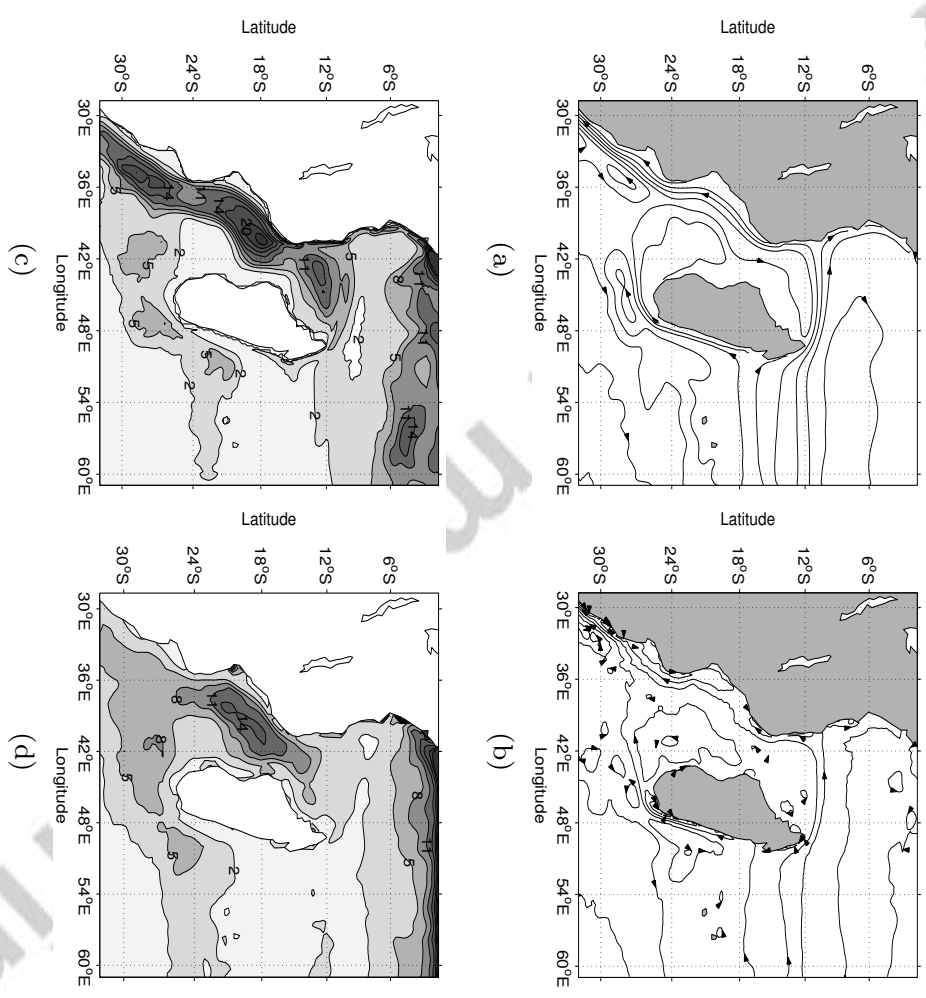

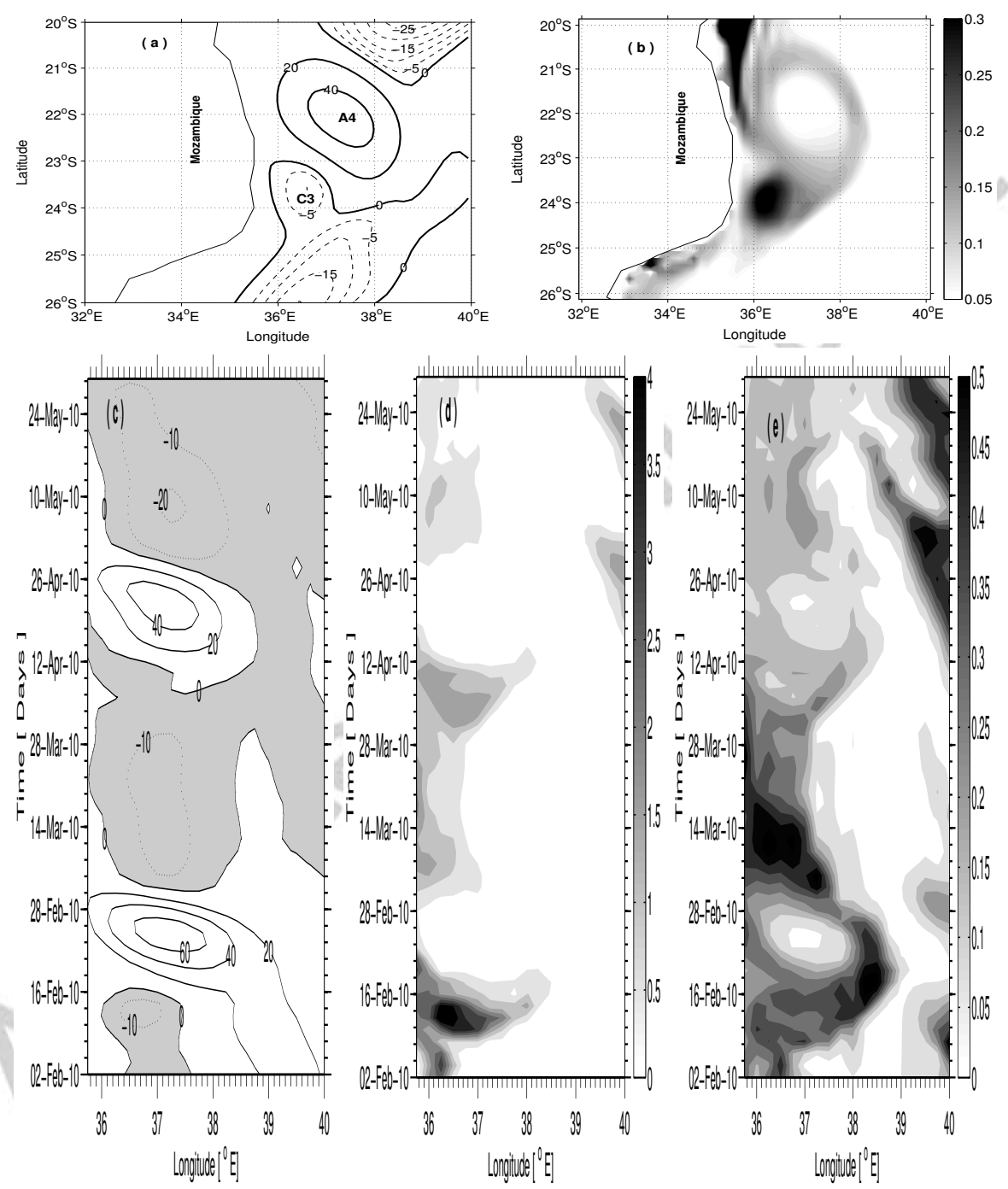